U. of Iowa $72-8$

\title{
Observed Relationships Between Electric Fields and Auroral \\ Particle Precipitation
}

by

D. A. Gurnett and I. A. Frank

\author{
Department of Physics and Astronomy \\ The University of Iowa \\ Iowa City, Iowa 52240
}

April 1972

REPRODUCTION IN WHOLE OR IN PART IS PERMITTED FOR ANY PURPOSE OF THE UNITED STATES GOVERNMENT

*This research was supported in part by the National Aeronautics and Space Administration under contracts NAS5-10625, NAS1-8141, and NASI-2973_and grant NGL16-001-002_and by the Office of Naval Research under contract N00014-68-A-0196-0003. 


\section{DOCUMENT CONTROL DATA - R\&D}

(Security classification of tille. body of abstract and indexinf annotation must be entered when the overall report is clas silied)

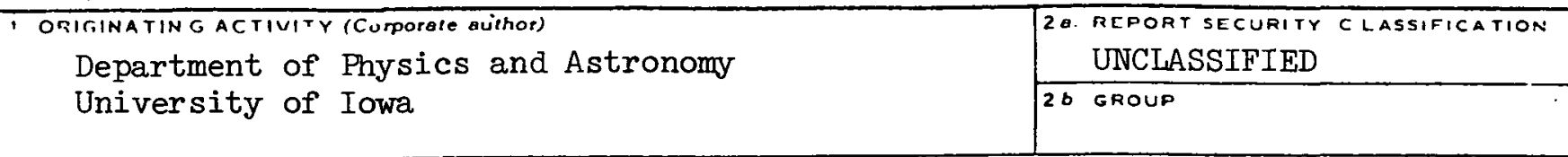
3. REPORT TITLE
"Observed Relationships Between Electric Fields and
Auroral Particle Precipitation"

4. DESCRIPTIVE NOTES (Type ol roport and inclusive dalos)

Progress, April 1972

5 AUTHOR(S) (Last name. first name. initial)

Gurnett, Donald A., and Louis A. Frank

\begin{tabular}{|c|c|c|}
\hline $\begin{array}{l}6 \text { REPORT DATE } \\
\text { April } 1972\end{array}$ & $\begin{array}{l}\text { 70. TOTAL NO. OF PAGES } \\
77\end{array}$ & $\begin{array}{l}\text { 7b. NO. OF REFS } \\
31\end{array}$ \\
\hline $\begin{array}{l}\text { 8a. CONTRACT OR GRANT NO. } \\
\text { NOOOI4-68-A-0196-0003 } \\
\text { B. PROJECT NO. }\end{array}$ & $\begin{array}{l}\text { 9a. ORIGINATOR'S REPOR } \\
\text { U. Of IOWA } 72-8\end{array}$ & BER(S) \\
\hline d. & $\begin{array}{l}9 \text { b. OTHER REPORT NO(S) } \\
\text { this report) }\end{array}$ & other numbers that may bo assignod \\
\hline
\end{tabular}

10. AVAILABILITY/LIMITATION NOTICES

Approved for public release; distribution is unlimited

11. SUPPLEMENTARY NOTES

12. SPONSORING MILITARY ACTIVITY

Office of Naval Research

13. ABSTRACT

[See following page] 


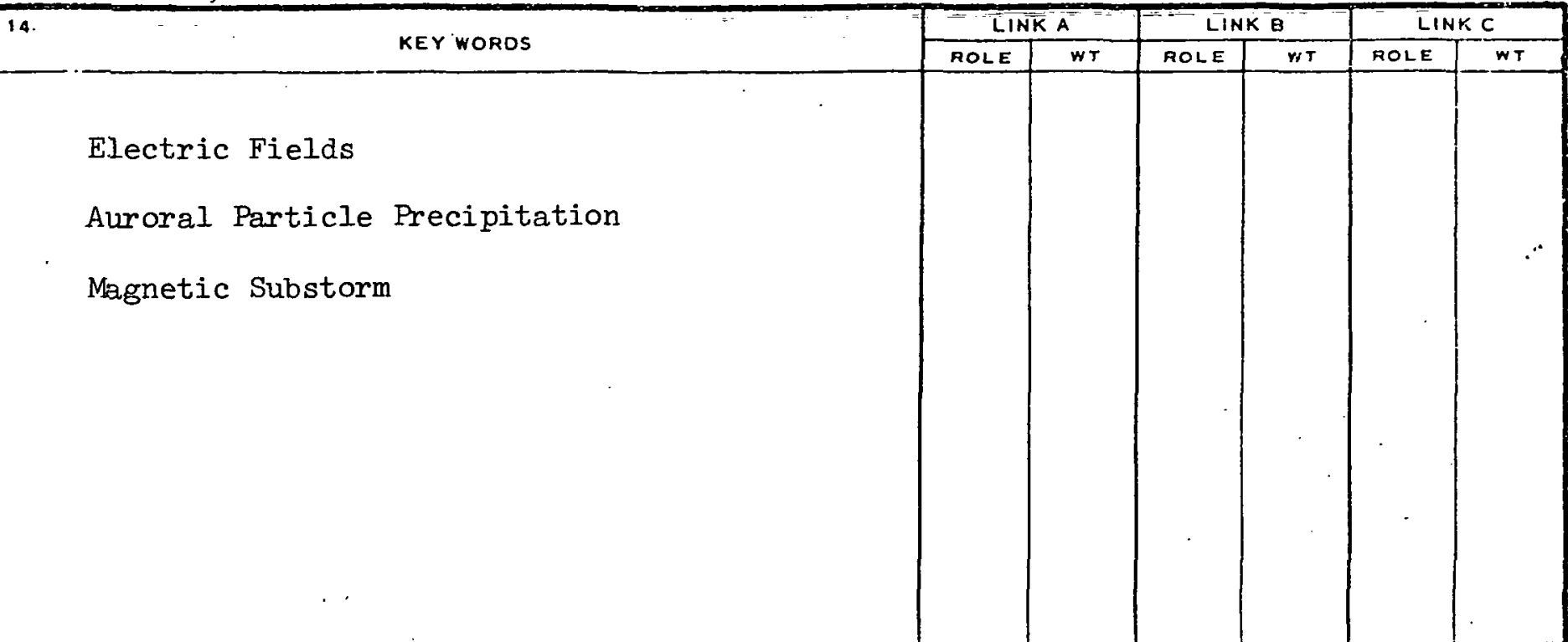

\section{INSTRUCTIONS}

1. ORIGINATING ACTIVITY: Enter the name and address of the contractor, subcontractor, grantec, Department of Defense activity or other organization (corporate author) issuing the report.

2a. REPORT SECURTY Cl.ASSIFICATION: Enter the overall security classification of the report. Indicate whether "Restricted Data" is included Markine is to be in accordance with appropriate security regulations.

2b. GROUP: Automatic downgrading is specified in DoD Directive 5200.10 and Armed Forces Industrial Manual. Enter the group number. Also, when applicable, show that optional markings have been used for Group 3 and Group 4 as authorized.

3. REPOR'T TITLE: Enter the complete seport title in all capital letters. Titles in all cases should be unclassified. If a meaningful title cannot be selected without classificetion, show title classification in all capitals in parenthesis immediately following the title.

4. DESCRIPTIVE NOTES: If appropriate, enter the type of report, e.g., interim, progress, summary, annual, or final.

Give the inclusive dates when a specific reporting period is covered.

5. AUTHOR(S): Enter the name(s) of author(s) as shown on or in the report. Enter last name, first name, middle initial. If nilititary, show rank and branch of service. The name of the principal author is an absolute minimum requirement.

6. REPORT DATE: Enter the date of the report as day, month, year; or month, year. If more than one date appears on the report, use date of publication.

7a. TOTAL NUMBER OF PAGES: The total page count should follow normal pagination procedures, i.e., enter the number of pages containing information.

7b. NUMBER OF REFERENCES. Enter the total number of references cited in the report.

8a. CONTRACT OR GRANT NUMBER: If appropriate, enter the applicable number of the contract or grant under which the report was written

8b, \&c, \& 8d. PROJECT NUMBER: Enter the appropriate military department identification, such as project number, subproject number, system numbers, task number, etc.

$9 a$. ORIGINATOR'S REPORT NUMBER(S): Enter the offirial report number by which the document will be identified and controlled by the originating activity. This number must be unique to this report.

9b. OTHER REPORT NUMBER(S): If the report has been assigned any other report numbers (either by the originator or by the sponsor), also enter this number(s).

10. AVAILABILITY/LIMITATION NOTICES: Enter any limitations on further dissemination of the report, other than those imposed by security classirication, using standard statements such as:

(1) "Qualified requesters may obtain copies of this report from DDC."

(2) "Foreign announcement and dissemination of this report by DDC is not authorized."

(3) "U. S. Government agencies may obtain copies of this report directly from DDC. Other qualified DDC users shall request through

(4) "U. S. military agencies may obtain copies of this report directly from DDC. Other qualified users shall request through

(5) "All distribution of this report is controlled. Qualified DDC users shall request through

"

If the report has been furnished to the Office of Technical Services, Department of Commerce, for sale to the public, indicate this fact and enter the price, if known.

11. SUPPLEMENTARY NOTES: Use for additional explanatory notes.

12. SPONSORING MILITARY ACTIVII'Y: Enter the name of the departmental project office or laboratory sponsoring (pay ing for) the research and development. Include address.

13. ABSTRACT: Enter an abstract giving a brief and factual summary of the document indicative of the report, even though it may also appear elsewhere in the body of the technical re-

port. If additional space is required, a continuation sheet shall be attached.

It is highly desirable that the abstract of classified reports be unclassified. Each paragraph of the abstract shall end with an indication of the military security classification of the information in the paragraph, represented as (TS), (S), (C), or (U).

There is no limitation on the length of the abstract. However, the suggested length is from 150 to 225 words.

14. KEY WORDS: Key words are technically meaningful terms or short phrases that characterize a report and may be used as index entries for cataloging the report. Key words must be selected so that no security classification is required. Identifiers, such as equipment model designation, trade name, military project code name, geographic location, may be used as key words but will be followed by an indication of technical context. The assignment of links, rales, and weights is optional. 


\section{ABSTRACT}

Simultaneous electric field and plasma observations with the low-altitude, polar orbiting satellite Injun 5 have provided a comprehensive survey of convection electric fields and their association with magnetospheric plasma phenomena. The most prominent features of the convection electric fields are reversals located at high magnetic latitudes, with generally anti-sunward convection poleward and sunward convection equatorward of the electric field reversal location. The electric field reversal is interpreted as the boundary between open and closed magnetic field lines.

During local day the electric field reversal is observed to coincide with the equatorward boundary of the polar cusp. The plasma flow in the dayside polar cusp region is dominantly east-west, away from the stagnation point, with convection velocities typically $\sim 1 \mathrm{~km}(\mathrm{sec})^{-1}$. At local evening "inverted $V^{\prime \prime}$ electron precipitation bands are observed near or at the position of the electric field reversal. In the local late-evening sector the electric field reversal becomes less distinct and often no single, well-defined electric field reversal can be identified. In all cases the "inverted V" electron precipitation events are closely associated with large, typically $>30 \mathrm{mV}(\mathrm{m})^{-1}$, irregular electric field fluctuations with 
time scales of a few seconds or less. Often these fluctuations comprise distinct "spikes" of a few seconds duration or less, which can be identified with distinct boundaries or other features of the electron precipitation. In the local midnight sector convection electric fields $>50 \mathrm{mV}(\mathrm{m})^{-1}$ associated with plasma-sheet electrons have been observed extending deep into the magnetosphere, equatorward of the electron ( $E>45 \mathrm{keV}$ ) trapping boundary. These convection electric fields are charactexized by considerably smaller fluctuations relative to those observed within the "inverted V" electron precipitation bands.

To investigate the electric field and plasma interrelationships during a polar magnetic substorm, a series of passes obtained prior to and during a substorm is presented. Large, anti-sunward convection velocities were detected over the polar cap several tens of minutes before the onset of the expansive phase of the substorm. These convection velocities gradually decreased during the decay phase of the substorm. Our measurements of enhanced anti-sunward flow over the polar cap region are generally consistent with several current ideas concerning the origin of substorms. 


\section{INTRODUCTION}

Electric field measurements with satellites [Cauffman and Gurnett, 1971; Heppner, 1972] and ionized Barium cloud releases [Haerendel and Lust, 1970; Wescott et al., 1969] have now established the primary features of magnetospheric plasma convection at low altitudes over the auroral zones and polar caps. See, for example, the reviews by Cauffman and Gurnett [1972] and Haerendel [1971]. Similarly, extensive measurements of low-energy auroral charged particles also have been acquired [see the review by Hultqvist, 1969] and a comprehensive spatial survey of the energy spectra and intensities of auroral charged particles has been presented by Frank and Ackerson [1972a]. However, until recently only a few simultaneous measurements of convection electric fields and auroral particle precipitation have been available for studying the relationship between these phenomena.

In a previous paper [Frank and Gurnett, 1971] an initial investigation of électric fields and charged particle observations was presented using data from the low-altitude satellite Injun 5 for orbits passing through the dawn-dusk local time sectors. This initial study revealed several important relationships between convection electric fields and the charged particle intensities. In particular, the "trapping boundary" for electrons with energies $\geqslant 45 \mathrm{keV}$ was found to be coincident with a reversal in the east-west direction of the 
plasma flow commonly observed in the high-latitude convection pattern, and intense "inverted $\mathrm{V}$ " electron precipitation bands of the type reported by Frank and Ackerson [1971] were observed at or poleward of the trapping boundary. The purpose of this paper is to present a detailed study of the relationship between electric fields and the auroral charged particle precipitation, particularly on the dayside of the magnetosphere and in the region of the intense "inverted $V^{\prime \prime}$. electron precipitation bands which most frequently constitute the primary auroral particle precipitation in the local afternoon and evening sectors. These latter observations will utilize the substantial telemetry capability of Injun 5 to make simultaneous, high-time resolution measurements of electric fields and auroral particle precipitation. A series of electric field and plasma observations obtained during a polar magnetic substorm is also analyzed to provide further information on the dynamical behavior of the magnetosphere during magnetic disturbances. 


\section{INSTRUMENTATION}

The satellite Injun 5 was launched on August 8, 1968, into a near-polar orbit with an apogee altitude of $2528 \mathrm{~km}$ and a perigee altitude of $677 \mathrm{~km}$. The electric field sensors on Injun 5 comprise two conducting spheres mounted on booms with a center-to-center separation of 2.85 meters. The spacecraft is oriented by a bar magnet within the spacecraft such that the electric antenna axis is always maintained approximately perpendicular to the local geomagnetic field vector. The electric field component parallel to the electric antenna axis is determined by measuring the potential difference between the spheres with a high-impedance voltmeter. See Gurnett et al. [1969] for a complete description of the electric field instrumentation on Injun 5. To determine the convection electric field in the plasma the $\vec{V}_{s} \times \vec{B}$ electric field caused by the spacecraft motion through the ionosphere and small instrumental errors must be subtracted from the measured electric field. Generally the accuracy of the convection electric field determination is limited to approximately $\pm 30 \mathrm{mV}(\mathrm{m})^{-1}$ by errors due to asymmetrical sunlight shadowing of the spheres by the supporting booms. However, for certain orientations and when the spacecraft is rotating very slowly, the accuracy of the electric field determination is much better, approximately $\pm 10 \mathrm{mV}(\mathrm{m})^{-1}$ or less [see 
discussions by Cauffman and Gurnett, 1971]. Except where noted all of the electric field data presented in this paper are selected for conditions when the convection electric field can be determined to an accuracy of $\pm 10 \mathrm{mV}(\mathrm{m})^{-1}$ or less.

Simultaneous measurements of electron and proton intensities within the energy range of $5 \leq \mathrm{E} \leq 50,000 \mathrm{eV}$ are provided by two Low-Energy Proton and Electron Differential Energy Analyzers (abbreviated LEPEDEA). These two electrostatic analyzers provide simultaneous measurements of the differential energy spectrums of proton and electron intensities within fields-of-view centered at pitch angles $\alpha=0^{\circ}$ and $\alpha=90^{\circ}$. Directional intensities of more energetic ( $E>45 \mathrm{keV}$ ) electrons are measured with a companion set of thin-windowed, Geiger-Mueller tubes. The spacecraft carries a tape recorder with a bit rate of 800 bits $(\mathrm{sec})^{-1}$ for worldwide spatial surveys and has a high bit-rate mode of operation at 24,000 bits $(\mathrm{sec})^{-1}$ for high-temporal resolution studies. Further description of the satellite and its charged particle instrumentation is given by Frank and Ackerson [1971]. 
III. POLAR CUSP OBSERVATIONS

From the observations of Frank [1971a] it is known that plasma from the dayside magnetosheath has direct access into the highlatitude magnetosphere through a region called the polar cusp. To illustrate the general relationship between the charged particle intensities and convection electric fields in the polar cusp region three polar passes have been selected for presentation. These passes were selected for presentation entirely on the basis of the quality of the electric field observations and without reference to the related charged particle intensities so that no known bias is present in the charged particle/electric field relationships shown. In each case it was required that the accuracy of the electric field determination be better than $+10 \mathrm{mV}(\mathrm{m})^{-1}$ and that a clearly defined electric field reversal, representative of the high-latitude electric fields observed with Injun 5, be detectable.

Figure 1 illustrates a meridional pass through the highlatitude dayside magnetosphere in the local early-afternoon sector. The polar cusp region, shown shaded in Figure 1, is easily identified in this case by the enhanced intensities of low-energy electrons $(105 \leq \mathrm{E} \leq 185 \mathrm{eV})$ and protons $(290 \leq \mathrm{E} \leq 455 \mathrm{eV})$ at $0850: 10$ to 0852:10 UT. From the intensities of electrons with energies $\mathrm{E}>45 \mathrm{keV}$ at pitch angles $\alpha=90^{\circ}$ shown in the bottom panel of 
Figure 1 it is seen that the polar cusp is located just poleward of the electron ( $E>45 \mathrm{keV}$ ) trapping boundary. This relationship is typical of polar cusp observations previously reported by Frank and Ackerson [1971, 1972a]. The polar cusp identification in this case is further supported by the simultaneous occurrence of broad-band VLF hiss in the polar cusp, as shown in the top panel of Figure 1. Gurnett and Frank [1972] have demonstrated that broadband VLF hiss, of the type show in Figure 1 , is associated with the relatively intense fluxes, $\mathrm{dJ} / \mathrm{dE} \geqslant 10^{4}$ to $10^{5}\left(\mathrm{~cm}^{2}-\mathrm{sec}-\mathrm{sr}-\mathrm{eV}\right)^{-1}$, of low-energy ( $100 \mathrm{eV}$ ) electrons in the polar cusp. The electric field measurements for this pass are shown in the second panel from the top in Figure 1. The convection electric field, $E_{c}$, is given by the difference between the measured electric field (solid line) and the $\vec{V}_{S} \times \vec{B}$ field (dashed line). Because of the slow rotation rate of the spacecraft and the absence of sunlight shadowing errors the convection electric field can be determined with exceptionally good accuracy, $\sim 5 \mathrm{mV}(\mathrm{m})^{-1}$, during this pass. A clearly defined electric field reversal is evident at 0850:10 UT, coincident with the electron ( $E>45 \mathrm{keV}$ ) trapping boundary and with the equatorward boundary of the polar cusp within the temporal resolution of these survey measurements. The spacecraft orientation near the reversal region is such that the electric antenna is measuring the north-south component of the convection electric field. The corresponding directions for the plasma convection velocity components 
are shown in the magnetic local time-invariant latitude (MLT-INV) polar diagram of Figure 2. The arrows in Figure 2 are in the directions of the convection velocity component detected and the length of the arrows is proportional to the magnitude of the convection velocity computed from $V_{c}=E_{c} / B$, where $E_{c}$ is the magnitude of the convection electric field component detected and $B$ is the scalar value of the local geomagnetic field. The negative electric field component of about $25 \mathrm{mV}(\mathrm{m})^{-1}$ at 0851 UT, poleward of the electric field reversal, corresponds to the eastward convection velocity component of about $1 \mathrm{~km}(\mathrm{sec})^{-1}$. Equatorward of the electric field reversal the convection is westward, toward the sun. Note from Figure 1 that although the maximum low-energy electron and proton intensities occur very near the electric field reversal, measurable proton intensities associated with the polar cusp are observed throughout the region of eastward (anti-sunward) convection poleward of the reversal. Over the polar cap, at about 0852:00 to 0857:00 UT, no convection electric fields greater than about $10 \mathrm{mV}(\mathrm{m})^{-1}$ are detectable. In the post-midnight sector a large region of westward convection is observed extending from 0857:00 to 0905:00 UT.

Figure 3 shows two additional polar passes selected to further demonstrate the relationship between convection electric fields and charged particle intensities in the polar cusp. The first pass, orbit 7561 , is very close to the local noon meridian. The polar cusp, shown shaded in Figure 3, is identified again by the dramatic 
enhancement of intensities of low-energy protons with energies $290 \leq \mathrm{E} \leq 455 \mathrm{eV}$ and $1030 \leq \mathrm{E} \leq 1610 \mathrm{eV}$, and electrons with energies $400 \leq \mathrm{E} \leq 705 \mathrm{eV}$, at 0830:00 to 0832:00 UT. The magnetic local time at the time of passage through the polar cusp is about 12.4 hours. The low-energy electron intensities in the polar cusp occur in a narrow latitudinal band, $\sim 2^{\circ}$ wide, adjacent to and poleward of the electron ( $E>45 \mathrm{keV}$ ) trapping boundary. The low-energy proton intensities are present in a somewhat broader latitudinal band, $\sim 3^{\circ}$ wide, which extends slightly poleward of the low-energy electron precipitation region. The characteristic soft energy spectrum of the polar cusp protons is evident in Figure 3 from the relative intensities of $290 \leq \mathrm{E} \leq 455-\mathrm{eV}$ and $1030 \leq \mathrm{E} \leq 1610-\mathrm{eV}$ protons.

The electric field for orbit 7561 has a clearly defined reversal located at 0830:00 UT. From Figure 3 it is seen that this electric field reversal is coincident with the location of the electron $(\mathrm{E}>45 \mathrm{keV}$ ) trapping boundary within the temporal resolution of these survey measurements. The MLT-INV polar diagram for the convection velocity components associated with this electric field reversal is shown in Figure 4. Equatorward of the electric field reversal a small zone of eastward convection is observed in a region of substantial electron $(E>45 \mathrm{keV})$ intensities at $\alpha=90^{\circ}$. Poleward of the electric field reversal there is a larger zone of generally westward plasma convection in a region void of electron $(E>45 \mathrm{keV})$ intensities. The polar-cusp plasma is located within this region of westward plasma convection just poleward of the electric 
field reversal and the electron ( $\mathrm{E}>45 \mathrm{keV}$ ) trapping boundary. At higher latitudes the convection velocity component decreases until it is essentially zero over the polar cap at 0833:00 to 0840:00 UT. It is important to note that the orientation of the electric field antenna changes by more than $90^{\circ}$ over the polar cap so that any convection electric field greater than about $10 \mathrm{mV}(\mathrm{m})^{-1}$ should have been detected. The second pass, orbit 6802, shown in Figure 3 is selected as an example of a polar cusp observation in the local morning sector at $\sim 0900 \mathrm{MLT}$. In this case the polar cusp location is best identified by the increase in the low-energy electron intensities. The lowenergy proton intensities observed in the polar cusp region during this pass are seen to be much lower than the two cases discussed above. The reduced low-energy proton intensities at this local time are typical of polar cusp observations at local times more than about 3 hours from local noon [Frank and Ackerson, 1972a]. The low-energy electron intensities in the polar cusp are again positioned in a narrow latitudinal band, about $3^{\circ}$ wide, poleward of and adjacent to the electron ( $E>45 \mathrm{keV}$ ) trapping boundary.

The convection electric field observed on orbit 6802 has a clearly defined reversal located at 2224:20 UT. From Figure 3 it is seen that the electric field reversal is again coincident with the electron ( $\mathrm{E}>45 \mathrm{keV}$ ) trapping boundary and the maximum polar-cusp electron and proton intensities. The convection velocity components associated with this electric field reversal are shown in the MLT-INV polar diagram of Figure 5. Equatorward of the electric field reversal a 
zone of eastward (sunward) convection is observed. This zone of sunward convection is within the region of measurable intensities of mirroring electrons ( $E>45 \mathrm{keV}$ ) equatorward of the trapping boundary. Poleward of the electric field reversal a larger zone of westward (anti-sunward) plasma convection is observed. This westward convection zone extends one or two degrees in latitude poleward of the detectable polar cusp plasma. Because of the low intensities of the polar-cusp protons relative to those of the local noon sector, it is difficult to accurately determine the poleward extent of the polar-cusp plasma at this local time solely from charged particle measurements. 
IV. DISCUSSION AND INTERPRETATION OF THE POIAR CUSP OBSERVATTONS

As shown by Cauffman and Gurnett [1972], the plasma convection in the dayside high-latitude auroral zone is primarily east-west and comprises a poleward zone and an equatorward zone separated by an electric field reversal. The east-west directions of the plasma convection are opposite in these two zones. Except in the region within about +2 hours of local noon, the east-west convection component is generally away from the sun in the poleward zone and toward the sun in the equatorward zone. The convection zones are generally only a few degrees wide in latitude near local noon, but increase considerably in width toward local evening and morning. In some cases the region of anti-sunward convection can expand over the entire polar region with relatively uniform anti-sunward convection velocities from dawn to dusk. In most cases, however, the anti-sunward convection is relatively non-uniform with the maximum convection velocities occurring in the region just poleward of the electric field reversal, particularly in the local dawn sector of the auroral zone (see Figure 7 of Caufman and Gurnett [1971], for example). The observed plasma convection pattern is broadly consistent with the flow pattern expected in the magnetospheric model recently proposed by us [Frank, 1971 a, b; Frank and Gurnett, 1971], which employs Dungey's [1961] concept of merging of geomagnetic field lines with those of the 
interplanetary magnetic field to provide access of magnetosheath plasma to the magnetospheric interior. In this interpretation, the electric field reversal occurs on the magnetic field line connecting with the merging region, the anti-sunward flow poleward of the electric field reversal is on "open" magnetic field lines which connect into the magnetosheath and solar wind, and the sunward flow equatorward of the electric field reversal corresponds to the return flow of "closed" magnetic field lines within the magnetosphere. Within about +2 hours of local noon, the east-west sense of the flow at low altitudes is not persistently the same on successive passes at a given magnetic local time, presumably due to the variations in the position of the distant neutral point at the magnetopause and the angle of attack of the solar wind.

The plasma convection observations shown in Figures 2 and 4 provide an excellent illustration of the convection pattern generally found on the dayside of the magnetosphere. The convection directions near the reversal at 0850:10 UT in Figure 2 are representative of conditions when the stagnation point is located west of the magnetic meridian through the spacecraft, thereby producing eastward convection away from the stagnation point on the poleward side of the reversal, and a westward return flow toward the stagnation point on the equatorward side of the reversal, as would be expected at this local time ( 13.6 hours $\mathrm{MLT}$ ). The convection directions observed for the reversal at 0830:00 UT in Figure 4, very close to local noon, are the opposite of those shown in Figure 2, indicating that in this case the 
stagnation point is located east of the spacecraft. Other observations [Cauffman and Gurnett, 1972] near local noon demonstrate that there is about equal probability of eastward or westward convection velocities in this region. The convection directions for the electric field reversal at 2224:20 UT in Figure 5 indicate that in this case the stagnation point is east of the spacecraft, as would be expected at this local time $(\sim 8.7$ hours MLT).

The polar cusp observations shown in Figures 2 and 5, together with the examples previously published by Gurnett and Frank [1972], provide a remarkably consistent picture of the association between convection electric fields and the polar cusp plasma. These measurements show that in all cases the electric field reversal is coincident, to within the accuracy of the determination, with the electron ( $E>45 \mathrm{keV}$ ) trapping boundary. The low-energy, polar-cusp protons with energies of several hundreds of $\mathrm{eV}$ are found to occur in a narrow latitudinal band, typically about $2^{\circ}$ wide, located just poleward of the electron ( $\mathrm{E}>45 \mathrm{keV}$ ) trapping boundary and extending into the region of anti-sunward flow poleward of the electric field reversal. It should be noted that without the full range of diagnostic capabilities available from Injun 5, it would be difficult to clearly determine the latitudinal width of the polar cusp region with the low-energy plasma observations alone. For example, for orbit 7561 of Figure 3 the low-energy (1030 $\leq \mathrm{E} \leq$ $1610 \mathrm{eV})$ proton intensities are significantly above the background levels at 0827:00 to 0832:00 UT. Both the convection electric field and the electron ( $E>45 \mathrm{keV}$ ) measurements, however, provide compelling 
evidence that the protons at 0827:00 to 0830:00 UT are on closed field lines within the magnetosphere and cannot be identified as polar cusp plasma. The relatively hard energy spectrum of the protons compared to the soft energy spectrum of the polar-cusp protons, evident in Figure 2, adds further confirming evidence of the proper identification of these two plasma regimes. Difficulties in distinguishing between these two plasma regimes because of limited diagnostic capabilities are believed to account for the large widths $\left(\sim 5^{\circ}\right)$ of the polar cusp observations by Heikkila and Winningham [1971] compared to the typical polar cusp widths $\left(\sim 2^{\circ}\right)$ obtained from Injun 5 (see also Frank and Ackerson [1972a]).

The low-energy ( $100 \mathrm{eV})$, polar-cusp electrons are observed in a narrow latitudinal band, typically $\leqslant 2^{\circ}$ wide, located within the low-energy proton band, with peak intensities usually near the equatorward boundary. A relatively rare example for which the polar cusp plasma is separated into a distinct equatorward "electron sheet" and a poleward "proton sheet", as is more often observed in the distant polar cusp [Frank, 197la], is given in Figure 1 of Gurnett and Frank [1972]. At the low altitudes of Injun 5, however, the electron band is usually embedded within the proton band as in Figures 1 and 3 . Typically the maximum intensities of low-energy, polar-cusp electrons are observed to be coincident with the electron ( $E>45 \mathrm{keV}$ ) trapping boundary and the electric field reversal.

Since the low-energy protons in the polar cusp are identified as the signature of the direct entry of magnetosheath plasma to low 
altitudes, these observations show that the region of generally anti-sunward plasma convection (away from the stagnation point) poleward of the electric field reversal is on "open" magnetic field lines which connect into the magnetosheath and solar wind. The presence of measurable intensities of mirroring electrons with energies $\gg 45 \mathrm{keV}$ equatorward of the electric field reversal lends considerable support to the interpretation that this region of generally sunward plasma convection (toward the dayside magnetopause) is on "closed" magnetic field lines. The intense fluxes of lowenergy ( $100 \mathrm{eV}$ to $1 \mathrm{keV}$ ) electrons often observed at the electric field reversal are believed to result from electron acceleration and heating in the merging region. 
V. OBSERVATIONS OF AURORAL PRECIPITATION IN THE LOCAL EVENING

Frank and Ackerson [1972a] have found that when the lowenergy electron precipitation band observed in the polar cusp is followed around into the local evening the average energy of the precipitated electrons increases to several $\mathrm{keV}$ or more. These electron precipitation bands are observed to have a characteristic inverted ' $V$ ' energy-time signature with the average electron energy increasing to a maximum and subsequently decreasing as the spacecraft passes through the precipitation region [Frank and Ackerson, 1971]. During periods of relative magnetic quiescence these "inverted V" events provide the primary charged particle energy input into the auroral zone in the local afternoon and evening and have been directly associated with visible auroral arcs [Ackerson and Frank, 1972]. To determine the relationship between the "inverted V" electron precipitation events and convection electron fields we have examined the observations from about 50 passes over the auroral zone at local afternoon and evening. Because the duration of the "inverted V" events is often only a few tens of seconds or less, only measurements acquired via the high bit-rate mode of operation were used in this part of the study. Since the telemetry station viewing range for high bit-rate acquisition is greatest when the satellite position attains its highest altitudes, most of this telemetry was obtained 
at relatively high altitudes $(\geqslant 1500 \mathrm{~km})$. Because the electron densities at high altitudes are often too low for satisfactory operation of the electric field experiment, the selection of high bit-rate telemetry suitable for electric field/charged particle comparisons was correspondingly limited. Essentially no auroral zone measurements obtained at altitudes above about $1800 \mathrm{~km}$ during local winter could be used because of the substantial levels of electric field "noise" commonly detected in this region [Cauffman and Gurnett, 1971]. Only measurements within regions where the electron densities are greater than about $10^{3}$ electrons $(\mathrm{cm})^{-3}$ were considered satisfactory for the electric field determinations in this study. Most of the observations examined here were obtained over the northern hemisphere during the summer of 1969.

From the cases studied a series of four passes has been selected to illustrate relationships which were either commonly observed or otherwise of special interest, as will be noted. The spacecraft orientation and rotation rate in each of these cases are such that the electric field can be determined with excellent accuracy, $<10 \mathrm{mV}(\mathrm{m})^{-1}$, with no possibility of spurious effects such as errors due to sunlight shadowing of the spheres or wake effects. No attempt was made to select these passes on the basis of magnetic activity, although in no case does the $K_{p}$ index exceed 3 . The passes are discussed in order of increasing local time.

\section{A. Orbit $\underline{5696}$}

The first pass selected for presentation, orbit 5696, crossed 
the northern auroral zone in the local evening sector at 18.8 hours magnetic local time. A color-coded energy-time spectrogram of the precipitated (pitch angle $\alpha=0^{\circ}$ ) electron intensities for this pass is show in Plate 1. The ordinate of this spectrogram is electron energy in units of $\mathrm{eV}$ and the abscissa is Universal Time [Frank and Ackerson, 1971]. The detector response is color-coded from blue to red (low to high detector responses) according to the log scale shown on the right-hand side of the spectrogram. During this pass two intense "inverted V" electron precipitation events are observed at about 0027:10 to 0028:30 UT. The average electron energy for the most energetic of these events extends up to several $\mathrm{keV}$ and substantial electron intensities can be seen at energies up to $15 \mathrm{keV}$ which is the upper limit for the spectrogram. The precipitated electron energy fluxes during this pass are shown in the bottom panel of Figure 6 . The "inverted $V "$ " events are located poleward of the electron ( $E>45 \mathrm{keV}$ ) trapping boundary which is indicated by the solid arrow at 0027:20 $(+10 \mathrm{sec})$ UT. The region of lower electron intensities positioned equatorward of the electron ( $\mathrm{E}>45 \mathrm{keV}$ ) trapping boundary, spanning the period 0026:20 to 0027:10 UT, and in the energy range extending up to several $\mathrm{keV}$ is identified as the low-altitude signature of the plasma sheet in the local evening sector [Ackerson and Frank, 1972]. The abrupt decrease of the precipitated electron intensities to near background- levels at 0027:35 ( $\pm 5 \mathrm{sec})$ UT evident in both Plate 1 and Figure 6, is not due to a loss of data or any other known instrumental effect. These "holes" in the precipitated electron intensities are occasionally 
encountered near the "inverted $V$ " events and are believed to be regions where the high intensities of upgoing low-energy $(\sim 100 \mathrm{eV})$ electrons reported by Gurnett and Frank [1972] occur.

The electric fields for this pass are shown in the top panel of Figure 6. A highly structured, electric field reversal is evident at 0027:45 to 0028:05 UT as the spacecraft passes through the major electron precipitation band. Although the relative variations in the electric field are accurate to about $\pm 10 \mathrm{mV}(\mathrm{m})^{-1}$ the spacecraft orientation on this pass cannot be determined with sufficient accuracy (due to the short duration of the pass) to give the $\vec{V}_{s} \times \vec{B}_{\text {field to }}$ this accuracy. The $\vec{V}_{S} \times \vec{B}$ field is therefore not shown in Figure 6 . our best estimates are that the maximum $\vec{V}_{s} \times \vec{B}_{\text {fields }}$ are about $-75 \mathrm{mV}(\mathrm{m})^{-1}$ in the vicinity of the reversal. As indicated in Figure 6, the electric antenna is oriented to detect the southeast-northwest component of the electric field during this pass. The overall change in the electric field at the position of the reversal (from northwest to southeast with increasing latitude) is consistent with the convection velocity directions usually observed at this local time (i.e., sunward flow equatorward of the electric field reversal and anti-sunward flow poleward of the electric field reversal). It is evident from Figure 6 that the reversal in the electric field directions, at about 0027:45 to 0028:05 UT, occurs coincident with the location of the most intense "inverted V" event encountered during this pass. Many large, impulsive fluctuations in the electric field are observed within and near the electric field reversal. As shown by the vertical 
guide lines in Figure 6, many of these impulsive variations appear to be associated with distinct features, boundaries and maxima, of the precipitated electron energy fluxes.

\section{B. Orbit $\underline{3716}$}

The second pass selected for presentation, orbit 3716 , occurs later in the local evening, at a local time of about 23.0 hours magnetic local time. The energy-time spectrogram for the precipitated electron intensities during this pass is shown in Plate 2. Several intense "inverted V" electron precipitation events appear in the energy-time spectrogram at 0702:20 to 0703:25 UT. The two most energetic of these events have average electron energies of several $\mathrm{keV}$ and substantial intensities at energies $>15 \mathrm{keV}$. At energies below about $1 \mathrm{keV}$, the electron precipitation is a relatively continuous band at 0702:20 to 0703:25 UT. As shown in the bottom panel of Figure 7, peak precipitation energy fluxes for these "inverted V" events are about 20 to 30 ergs $\left(\mathrm{cm}^{2}-\mathrm{sec}-\mathrm{sr}\right)^{-1}$. The "inverted V" electron precipitation events are again located poleward of the electron ( $\mathrm{E}>45 \mathrm{keV}$ ) trapping boundary (see Figure 7). The broad zone of lower electron intensities near and equatorward of the electron $(E>45 \mathrm{keV})$ trapping boundary, at about 0703:25 UT to the end of the pass at 0707:25 UT, is identified as the low-altitude signature of the plasma sheet via the energy spectrums and intensities of these precipitated electrons. As is seen from Figure 7, the peak precipitated energy fluxes of the "inverted V" events are factors of 5 , or more, greater than the precipitated energy fluxes of the plasma-sheet electrons. 
Reference to the top panel of Figure 7 shows that the primary convection electric fields observed on this pass are confined to the region near the "inverted $V^{\prime \prime}$ events. Because of the absence of sunlight shadowing errors and the slow rotation of the spacecraft, the $\vec{V}_{S} \times \vec{B}$ field can be determined with excellent accuracy, $\pm 10 \mathrm{mV}(\mathrm{m})^{-1}$, on this pass. No single, well-defined electric field reversal is evident for this pass. However, a persistently southward electric field. component of up to $\sim 50 \mathrm{mV}(\mathrm{m})^{-1}$ is observed from about 0701:30 to 0702:00 UT, just poleward of the "inverted V" events and a northward electric field component of up to $\sim 30 \mathrm{mV}(\mathrm{m})^{-1}$ is observed at 0703:25 to 0703:50, just equatorward of the "inverted V" events. These electric field directions correspond to eastward (anti-sunward) convection on the poleward side of the "inverted V" events and westward (sunward) convection equatorward of the "inverted V" events. These convection directions are again consistent with the plasma flow directions usually observed on either side of an electric field reversal. We therefore identify the region of the "inverted $V$ " events in Figure 7 as being coincident with a small, rather poorly defined, electric field reversal.

In the region of the electric field reversal many large, irregular fluctuations in the electric field, of the order of $\pm 50 \mathrm{mV}$ $(m)^{-1}$, are observed with time scales of a few seconds. In several cases these irregular variations are closely related to well-defined boundaries of the "inverted $\mathrm{V}^{\prime \prime}$ electron precipitation bands. For example, the "inverted $V$ " event at 0703:15 UT is bounded by a brief (1 sec), $50 \mathrm{mV}(\mathrm{m})^{-1}$ southward spike in the electric field at the 
poleward boundary of the event (0703:10 UT) and by a similar northward spike at the equatorward boundary (0703:20 UT). In this case the "inverted $V$ " band occurs in a region with a large latitudinal gradient in the north-south electric field (corresponding to a shear in the east-west plasma flow) between these two spikes. The "inverted V" event at 0702:50 UT also appears to be associated with a large latitudinal gradient in the north-south electric field, although the detailed association is not as discernible in this case. No convection electric fields are detectable in the plasma sheet region during this pass.

$$
\text { C. Orbit } 3667
$$

The third pass selected, orbit 3667 , is positioned near local midnight. The energy-time spectrogram for the precipitated electron intensities during this pass is shown in Plate 3. A notably intense "inverted V" electron precipitation event is evident in this spectrogram at 0622:55 to 0623:25 UT. Several less distinct "inverted V" bands with maximum energies of a few $\mathrm{keV}$ are also evident at 0623:25 to 0624:45 UT. As shown in Figure 8, the electron energy flux for the most intense of these events is about 20 ergs $\left(\mathrm{cm}^{2}-\mathrm{sec}-\mathrm{sr}\right)^{-1}$. As usual, the "inverted $V "$ events are located poleward of the electron ( $E>45 \mathrm{keV}$ ) trapping boundary.

The region of lower electron intensities encountered at 0624:45 to 0627:30 UT, equatorward of the electron ( $\mathrm{E}>45 \mathrm{keV}$ ) trapping boundary, is again identified as the plasma sheet. The maximum 
precipitated electron energy flux in the plasma sheet region is about 6 ergs $\left(\mathrm{cm}^{2}-\mathrm{sec}-\mathrm{sr}\right)^{-1}$, larger than in the previous two plasma sheet observations, but again significantly less than the peak precipitated energy flux in the "inverted V" band. The equatorward termination of the plasma sheet can be readily seen at 0627:30 UT in both Plate 3 and Figure 8 .

The electric fields for this pass are shown in the top panel of Figure 8. Again the electric field can be determined with an accuracy of $\pm 10 \mathrm{mV}(\mathrm{m})^{-1}$ or better. As seen from Figure 8 , measurable convection electric fields are detected within both the "inverted V" and plasma sheet zones during this pass. The electric field in the "inverted $V^{\prime \prime}$ region is again characterized by large, $\sim 50 \mathrm{mV}(\mathrm{m})^{-1}$, irregular fluctuations with time scales of a few seconds. The most striking features of these electric field variations are the $\sim 125 \mathrm{mV}$ $(\mathrm{m})^{-1}$ spike in the south-eastward electric field component at 0622:55 UT and a very similar, but oppositely directed (north-westward) spike at 0623:50 UT. The onset of the first, south-eastward spike is coincident, within the accuracy of the determination, with the poleward boundary of the major "inverted V" event. As shown by the vertical guide lines in Figure 8 the second, north-westward, spike is coincident with the equatorward boundary of this "inverted V" band. The electric field between these two spikes is very irregular but does appear to have an overall gradient from southeast to northwest as the spacecraft moves equatorward. Despite the remarkable latitudinal symmetry of the electric field associated with these two spikes 
the "inverted $V "$ event is not located symmetrically with respect to the electric field variations. As shown in Figure 8 , the maximum energy fluxes for the "inverted $V^{\prime \prime}$ event are located poleward of the midpoint between these two spikes. Further equatorward, at 0623:50 to about 0624:40 UT, more irregular fluctuations in the electric field of lesser amplitudes are observed and are associated with relatively moderate electron precipitation events.

When the spacecraft enters the plasma sheet at about 0624:45 UT the large, irregular electric field fluctuations characteristic of the "inverted V" electron bands abruptly terminate and the electric field variations become relatively smooth. Within this plasma sheet region, the convection electric field is less than $10 \mathrm{mV}(\mathrm{m})^{-1}$ near the poleward boundary, but increases to approximately $65 \mathrm{mV}(\mathrm{m})^{-1}$ near the equatorward boundary of the plasma sheet. The latter electric field component is in the south-eastward direction and corresponds to a north-eastward convection velocity component of about $2.9 \mathrm{~km}$ $(\mathrm{sec})^{-1}$. At the equatorward boundary of the plasma sheet the convection electric field abruptly decreases to zero, as shown by the vertical guide line at 0627:35 UT in Figure 8. The plasmapause is located at 0628:15 (+30 sec) UT, nearly coincident with the equatorward boundary of the plasma sheet. The plasmapause location is identified in this case by a "break-up" of the lower hybrid resonance noise band, known to occur at the plasmapause boundary [Carpenter et aI., 1968], and by an abrupt increase in electron densities simultaneously monitored with the AFCRL electron density instrument on Injun 5. 
A very similar example of large convection electric fields near the equatorward termination of the plasma sheet is found in Figure 1 at 0903:00 to 0905:00 UT.

\section{Orbit $\underline{3655}$}

The fourth pass selected for discussion, orbit 3655, traverses the auroral zone at approximately 0.5 hours magnetic local time and has been chosen to further illustrate phenomena within the midnight sector. The energy-time spectrogram for the precipitated electron intensities during this pass is shown in Plate 4. The electron $(E>45 \mathrm{keV})$ trapping boundary is located at 0645:20 ( $+10 \mathrm{sec})$ UT as shown by the arrow at the bottom of Figure 9 . On this pass a single "inverted $V^{\prime \prime}$ precipitation band with moderate intensities is located just poleward of the trapping boundary, at 0644:40 to 0645:15 UT. The region equatorward of the trapping boundary, at 0645:15 to 0647:30 UT, is again identified as the plasma sheet from the characteristic spectrums and intensities of the plasma-sheet electrons and their location equatorward of the trapping boundary. For this example, the maximum precipitated electron energy flux in the "inverted $V$ " band is less than that within the plasma sheet region, as is typical of the auroral charged particle precipitation observed in the local post-midnight and dawn sectors [Frank and Ackerson, 1972a]. As can be readily seen from Figure 9, the electron energy fluxes in the plasma sheet have quasi-periodic pulsations with periods of about 10 seconds. These pulsations are also seen in the spectrogram of Plate 4, especially at energies above about $1 \mathrm{keV}$, and in the 
electron ( $E>45 \mathrm{keV}$ ) intensities (not shown here). Frank and Ackerson [1972b] have determined the length of the magnetic field line from the spacecraft to the corresponding mirror point in the opposite hemisphere during this pass from the echo time of identifiable packets of electrons with $\mathrm{E}>45 \mathrm{keV}$ associated with these pulsations. Such observations showed that the magnetic field line length, from mirror point to conjugate mirror point, varied from about 25 earth radii at 0646:44 UT, to 50 earth radii at 0646:23 UT for the most intense segment of electron precipitation from the plasma sheet. The corresponding geocentric radial distances at the magnetic equator for these field lines are 10 and 20 earth radii, respectively, in the dipole approximation. Frank and Ackerson [1972b] present substantial evidences that pulsating auroras $\left(P_{1}\right)$ can be attributed to such fluctuations of plasma-sheet energy fluxes as those shown in Figure 9.

The electric fields for this pass are shown in the top panel of Figure 9. Significant deviations of the measured electric field from the $\vec{V}_{s} \times \vec{B}$ field are evident throughout the "inverted $V^{\prime \prime}$ and plasma sheet zones. In contrast to the three previous examples, the electric field variations are relatively smooth with only small, $<10 \mathrm{mV}(\mathrm{m})^{-1}$, fluctuations on a time scale of a few seconds or less. The most prominent electric field effect for this pass is the large. southward electric field component detected at about 0644:30 to 0644:55 UT. This electric field corresponds to a zone of eastward convection and is associated with the moderate "inverted $V$ " event 
positioned just poleward of the trapping boundary. As for previous examples, the spatial features of the electric fields and of the "inverted $V "$ event are not exactly congruent. The maximum in the in the convection electric field is positioned slightly poleward of the most energetic part of the "inverted V" event. However, the "inverted $V "$ band is again located within a region which has a large latitudinal gradient in the north-south electric field. In the plasma sheet a small, $\sim 30 \mathrm{mV}(\mathrm{m})^{-1}$, southward electric field is observed which decreases to zero at the equatorward boundary of the plasma sheet at 0647:20. The electric field variations within the plasma sheet are quite different from those observed for orbits 7476 (Figure 1) and 3667 (Figure 8) for which the electric fields reach a maximum near the equatorward boundary of the plasma sheet. No fluctuations of the electric field are found which can be associated with the pulsations of plasma-sheet energy fluxes. 


\section{DISCUSSION AND INTERPRETATION OF LOCAL EVENING OBSERVATIONS}

In the dayside polar cusp at low altitudes the intense lowenergy $(\sim 100 \mathrm{eV})$ "inverted $V$ " electron precipitation bands are positioned at the electric field reversal and the electron ( $E>45 \mathrm{keV}$ ) trapping boundary. This general relationship is also observed frequently for the more energetic ( 1 to $10 \mathrm{keV}$ ) "inverted $V^{\prime \prime}$ electron precipitation events at local evening (see Figure 6, for example). The "inverted $\mathrm{V}^{\prime \prime}$ bands are broader in these later local-time sectors and are located typically in a region adjacent to and poleward of the trapping boundary. However, these bands have also been observed at latitudes substantially above the trapping boundary [cf. Frank and Ackerson, 1972a]. At still later local times, in the late-evening and pre-midnight sectors, the electric field reversals are smaller and less distinct and in many cases a single, well-defined electric field reversal cannot be identified (see Figures 7, 8, and 9 as examples). When a clearly defined electric field reversal can be identified, an "inverted V" electron precipitation event is usually positioned at the electric field reversal. Although the dominant, precipitated electron'energy fluxes in the local evening are due to the "inverted. $V^{\prime \prime}$ bands, smaller but still significant electron precipitation is also found in the plasma sheet region equatorward of the electric field reversal. From the standpoint of comparing these results with 
ground-based observations it is important to note that, although the most intense auroral arcs are usually produced by the "inverted V" events at the electric field reversal, visible auroral emissions can also be expected from the plasma-sheet electrons precipitated in the region of generally sunward convection equatorward of the electric field reversal, particularly during the expansive phase of a polar magnetic substorm.

For all cases investigated here in the local afternoon and evening sectors the "inverted V" electron precipitation events are found to be associated with large, typically $>30 \mathrm{mV}(\mathrm{m})^{-1}$, irregular electric field fluctuations with time scales of a few seconds or less. These electric field fluctuations are normally confined to the immediate vicinity of the "inverted $V$ " events, as in Figure 7 and 8 . In many cases these irregular fluctuations provide such a distinctive "signature" that the location of the "inverted $V^{\prime \prime}$ events could be predicted with good reliability from the electric field measurements alone without prior reference to the plasma observations. Often these electric field variations appear to comprise one or more pairs of oppositely directed "spikes", of a few seconds duration or less, each of which are usually identified with distinct boundaries of the electron precipitation region (see Figure 8 at 0622:55 and 0623:50 UT, for example). The abrupt changes in the electric field at the boundaries of the precipitation region may correspond to the abrupt rotation in the electric field direction observed on rocket flights [Mozer and Fahleson, 1970; Choy et al., 1971] near the boundaries of an auroral arc. It is of interest to note that these oppositely directed spikes 
in the north-south component of the electric field, as in Figure 7 at 0702:35 to 0702:50 UT, correspond to a decrease in the electrostatic potential within the "inverted $V "$ region. The "inverted V" events, however, are usually not located symetrically relative to the spatial configuration of these oppositely directed electric fields. In most cases the energetic part of the "inverted $V^{\prime \prime}$ event occurs where a large latitudinal gradient exists in the north-south electric field component (see Figure 9 at 0644:45 UT, for example). Within the energetic part of the "inverted $V$ " event the electric field can be quite large, $>50 \mathrm{mV}(\mathrm{m})^{-1}$, (see Figure 7 at 0702:50 UT, for example) in contrast to various rocket measurements of electric fields at lower altitudes [Aggson, 1969; Potter, 1970] which indicate that the electric field is small, $<10 \mathrm{mV}(\mathrm{m})^{-1}$, within an auroral arc. These contrasting results at different altitudes could be taken as evidence for an electric field component parallel to the geomagnetic field. However, other rocket measurements [Mozer and Fahleson, 1970] have shown that larger, $\sim 30 \mathrm{mV}(\mathrm{m})^{-1}$, electric fields are also observed in auroral arcs. Because of the relatively few rocket measurements of electric fields within auroral arcs in the ionosphere and the uncertainty. as to whether these flights pass through "inverted $\mathrm{V}$ " events comparable to those detected by Injun 5, we feel that no firm conclusions can be drawn about the presence of electric fields directed parallel to the geomagnetic field from the above body of observations.

In the plasma sheet, equatorward of the electron ( $\mathrm{E}>45 \mathrm{keV})$ trapping boundary, the electric field variations are quite different 
from those in the "inverted V" electron precipitation bands. The electric field in the plasma sheet is. usually relatively smooth on a time scale of tens of seconds (or a horizontal distance scale of hundreds of $\mathrm{km}$ ) or less with no evidence of the large-amplitude electric field fluctuations such as those encountered in the "inverted $V^{\prime \prime}$ region (compare these two regions in Figure 8, for example). In the local dawn and dusk sectors the convection velocities in the plasma sheet are generally sunward since the plasma is located on closed geomagnetic field lines equatorward of the electric field reversal [Frank and Gurnett, 1971]. In the local midnight sector the convection electric field is highly variable with marked changes in both magnitude and direction from pass to pass. In Figure 7, for example, no convection electric field is detectable within the plasma sheet during this pass. The plasma sheet observations of Figures 1 and 8, on the other hand, are characterized by relatively large convection velocities near the equatorward boundary of the plasma sheet. However, the directions of the convection velocity components detected in the plasma sheet are different for these two cases (westward in Figure 1 and north-eastward in Figure 8). The variability in the east-west direction of the convection velocity near local midnight is probably due to the fluctuations in the east-west location of the stagnation point for the generally sunward flow of plasma from the geomagnetic tail. The large convection velocities, $\sim 3 \mathrm{~km}(\mathrm{sec})^{-1}$, at the equatorward boundary of the plasma sheet may mean that convection electric fields are more 
important than previously thought for the transport, loss, and deenergization of plasma-sheet charged particles penetrating into this region of the magnetosphere [see discussions by Vasyliunas, 1968; Kennel, 1969]. 
VII. OBSERVATIONS DURING A POIAR MAGNETIC SUBSTORM

In this section we present a series of low-altitude observations during a polar magnetic substorm. The substorm of interest here occurred at 1530 to 1900 UT on February 24, 1970. Several factors contribute to make the satellite measurements during this event particularly useful for investigating electric field and plasma phenomena associated with a substorm. First, the magnetic signature of this substorm is exceptionally clear. The magnetic disturbances during this storm have a well-defined onset and are preceded by a period of several hours during which no significant magnetic activity is observed. Second, essentially continuous world-wide observations are available in the dawn-dusk meridional plane both prior to and during this event. Third, the spacecraft rotation rate, orientation, and altitude are such that the ( north-south) convection electric field can be determined with an accuracy of better than $+10 \mathrm{mV}(\mathrm{m})^{-1}$ over both the northern and southern hemispheres during the substorm.

Superposed H-traces from the magnetograms of a series of selected auroral zone observatories are shown in Figure 10 for the period of this polar magnetic substorm [S.-I. Akasofu, private communication]. The difference between the upper trace (AU) and the lower trace (AL) of the envelope is the auroral electrojet activity index, AE. The onset of the substorm is clearly signaled 
by the abrupt increase in the AE index at about 1530 UT. Following the onset of the substorm, a negative bay of about 500 gammas is observed at numerous auroral zone magnetic observatories in the local evening and midnight sectors. The magnetic disturbances associated with this substorm reach a maximum at 1600 to 1630 UT and recover to the pre-storm values at about 1900 UT.

The convection velocity components for three consecutive polar passes during the initial phases of the substorm are shown in Figure 11. The northern hemisphere polar pass of orbit 6871 , shown in the top polar diagram of Figure 11, occurs well before the onset time of the substorm. The convection velocities during this pass are generally small except for a small region at the local morning at about $80^{\circ}$ invariant latitude. The next polar pass, over the southern hemisphere on orbit 6871, is shown in the middle polar diagram of Figure 11. This pass is nearly coincident with the onset of the substorm (see Figure 10). Very large convection velocities, $\geqslant 3 \mathrm{~km}(\mathrm{sec})^{-1}$, are detected over the polar region during this pass. The plasma convection during this pass comprises a large zone of anti-sunward flow over the polar cap and adjacent zones of sunward flow at lower latitudes in the local morning and evening sectors. These zones of sunward and antisunward flow are separated by electric field reversals at about 1519:00 and 1533:00 UT. The anti-sunward convection velocities over the polar. cap for this pass are unusually large and are not commonly encountered with Injun 5. However, similar cases with nearly uniform, antisunward convection velocities over the polar cap have been reported 
previously (see Figure 7 of Cauffman and Gurnett [1971], for example). The next polar pass, over the northern hemisphere on orbit 6872 , is shown in the bottom diagram of Figure 11. This pass occurs about one hour after the onset of the substorm and shortly after the time of maximum magnetic disturbance. The convection velocities during this pass are again in the anti-sunward direction over the polar cap and in the sunward direction at lower latitudes. These zones of oppositely-directed plasma flow are separated by electric field reversals located at about $1624: 30$ and 1634:00 UT. The convection velocities, $\sim 1.5$ to $2.0 \mathrm{~km}(\mathrm{sec})^{-1}$, are smaller and less uniform over the polar cap relative to those of the preceding pass over the southern hemisphere. The equatorward boundary of the sunward convection zone at local evening has also shifted from $\sim 70^{\circ}$ to $\sim 59^{\circ}$ INV during the time interval, 75 minutes, between these latter two passes (see Figures 12 and 13). The electric fields for subsequent passes during the recovery phase of the substorm display a general trend toward smaller convection velocities, $\leqslant 0.75 \mathrm{~km}(\mathrm{sec})^{-1}$ by 1900 UT, with less uniformity in the zone of anti-sunward plasma flow over the polar cap.

The electric field and charged particle observations for the southern hemisphere pass of orbit 6871 , near the onset of the substorm are shown in Figure 12. The electric field reversals separating the regions of sunward and anti-sunward plasma flow are evident in the top panel of Figure 12 at about 1519:00 and 1533:00 UT. The electron ( $\mathrm{E}>45 \mathrm{keV}$ ) trapping boundary at local evening, shown by the vertical 
dashed line at 1516:00 UT, is located within the zone of sunward convection several degrees equatorward of the electric field reversal. This relationship is very unusual since, as shown previously by Frank and Gurnett [1971], the electron ( $\mathrm{E}>45 \mathrm{keV}$ ) trapping boundary is typically positioned coincident with the electric field reversal, to within the accuracy of the determination. The electron ( $E>45 \mathrm{keV}$ ) trapping boundary in this caise clearly does not coincide with the boundary between open and closed magnetic field lines since the sunward plasma flow equatorward of the electric field reversal occurs on closed magnetic field lines [Frank and Gurnett, 1971]. In fact since the most probable source of magnetospheric plasmas in these regions is the magnetosheath which is known to be relatively void of these more energetic electron intensities, there is no compelling reason to believe that all closed field lines must be always populated with measurable intensities of these energetic electrons, particularly with respect to regions of newly injected plasma within the plasma sheet. This sunward plasma flow in the local evening sector is also associated with a region of enhanced low-energy electron and proton intensities as shown by the shaded band in Figure 12. From the relatively soft energy spectrums and overall intensities of these particles and their location on closed magnetic field lines, the region encountered at 1516 to 1518 UT is observationally identified with the plasma sheet adjacent to the downstream magnetosheath along the evening flanks of the magnetosphere [cf. Figure 7 of Frank and Girnett, 1971]. The enhanced intensities of lower energy electrons and of $1030 \leq \mathrm{E} \leq$ 
2040-eV protons within this zone are believed to be those of magnetosheath plasma which is being injected into the plasma sheet. The intensities of higher energy protons (11.0 $\leq E \leq 17.4 \mathrm{keV})$ at 1513 to 1516 UT are to be identified as the signature of the earthwara extension of the plasma sheet, the extraterrestrial ring current. The latitudinal distribution of the plasma-sheet electron intensities, the location of the electron ( $E>45 \mathrm{keV}$ ) trapping boundary, and the penetration of the ring-current protons to lower I values than the plasma-sheet electrons are in substantial agreement with the spatial structure of the near-earth plasma sheet reported by Frank [1971c] at similar local times with high-altitude measurements near the magnetic equatorial plane.

The electric field and charged particle observations at approximately one hour later, during the northern hemisphere pass of orbit 6872, are shown in Figure 13. The electric field reversals separating the regions of sunward and anti-sunward plasma flow are well-defined and located at 1624:30 and 1634:00 UT. The positions of the two electron $(\mathrm{E}>45 \mathrm{keV})$ trapping boundaries are shown by the vertical dashed lines in Figure 13. In contrast to the preceding pass, the electric field reversal and the trapping boundary in the local evening sector of this pass are located more nearly coincident, within $\sim 2^{\circ}$ INV of each other. However, the electron $(E>45 \mathrm{keV})$ intensities are seen to have changed severely within the outer radiation zone during the time interval between these two passes. By comparing Figures 12 and 13, it can be seen that the electron ( $E>45 \mathrm{keV}$ ) 
intensities decreased by approximately one order of magnitude at local evening and increased by approximately one order of magnitude at local morning. Craven [1966] has reported similar observations of abrupt depletions of the outer radiation zone electron intensities at low altitudes during magnetic storms. Since no similarly spectacular depletion of the outer zone electron intensities has been reported for measurements near the magnetic equatorial plane to our knowledge, it is presumed that this "depletion" effect observed at low altitudes involves principally only electrons with pitch angles within and near the loss cone.

The abrupt increase of electron ( $E>45 \mathrm{keV}$ and $1160 \leq \mathrm{E} \leq$ $2040 \mathrm{eV}$ ) intensities at 1633:45 ( $\pm 15 \mathrm{sec}$ ) UT, poleward of the trapping boundary in the local evening sector, is attributed to an energetic "inverted V" electron precipitation band [cf. Frank and Ackerson, 1972a]. Although the detailed "inverted V" energy-time structure cannot be resolved with these low bit-rate observations, several characteristic features allow us to identify this intensity increase as an "inverted $V^{\prime \prime}$ type event. These characteristics include the location of the event poleward of the trapping boundary, the electron energy spectrum and intensities, and the angular distribution of the electron intensities. Note that this "inverted $V^{\prime \prime}$ event is also associated with an abrupt change in the ( north-south). electric field at about 1633:30 UT, similar to those of the electric field observations of orbit 5696 displayed. in Figure 6. As shown by the electron intensities at $250 \leq \mathrm{E} \leq 440 \mathrm{eV}$ and 
$1160 \leq \mathrm{E} \leq 2040 \mathrm{eV}$ of Figure 13 enhanced intensities of low-energy (100 eV to I keV) electrons are observed throughout the region of antisunward convection at 1624:30 to 1634:00 UT. The electron intensities are nearly uniform at intensity levels which are more than an order of magnitude greater than the threshold intensity for the detector in these energy ranges over the polar caps. These electron intensities are anisotropic with the intensities at pitch angles $\alpha=90^{\circ}$ factors $\sim 5$ less than those at $\alpha=0^{\circ}$. Normally, the electron intensities observed over the polar caps are at or near the intensity threshold of the detector for these energy ranges. For example, no comparable electron intensities are observed over the southern polar cap region during the pass shown in Figure 12, or during the preceding northern hemisphere pass two hours earlier. Measurements for the remaining polar passes during the substorm recovery show that the enhanced polarcap electron intensities continue to be present for a period of about two hours over the northern polar cap at somewhat lesser intensities. However, comparable electron intensities are not observed over the southern polar cap for any pass during this event. Thus, a pronounced north-south asymmetry appears to exist for the intensities of this low-energy, polar cap electron precipitation. This asymmetry for the polar cap intensities during substorm and quiescent periods will be discussed more thoroughly in a future report.. 


\section{DISCUSSION AND INTERPRETATION OF THE SUBSTORM OBSERVATIONS DURING FEBRUARY 24, 1970}

The simultaneous electric field and plasma measurements reported here for the polar magnetic substorm of February 24, 1970, delineate several important new features of magnetospheric electric fields and their relationship to the dynamical processes occurring during a polar magnetic substorm. As discussed by Rostoker [1972], the development of a substorm may be described in terms of three basic phases, the growth phase, the expansive phase, and the decay phase. The expansive phase is characterized by the poleward motion of visible auroral arcs [Akasofu, 1968] and a rapid intensification of the ionospheric current system over a period of a few minutes. The sudden onset of the magnetic perturbations evident in Figure 10 at 1540:00 ( $+5 \mathrm{~min}$. ) UT is identified as the start of the expansive phase of this substorm. The growth phase of a substorm is associated with a small increase in magnetic activity [McPherron, 1970] over a period of several tens of minutes preceding the expansive phase and is presently believed to be a signature of the injection of energy into the nightside magnetosphere. Careful inspection of the magnetograms of Figure 10 shows that the first recognizable magnetic activity associated with this storm occurred at 1430:00 ( \pm 10 min.)-UT. Correspondingly, the relatively moderate magnetic activity at $\sim 1430$ to 1540 UT preceding the expansive phase is identified here with the 
growth phase of the substorm. The decay phase of a substorm follows the expansive phase and typically lasts for one to two hours. The decay phase of the February 24, 1970, substorm is readily identified in Figure 10 and spans the period 1600 to 1900 UT.

An examination of the sequence of events during this particular substorm shows that the large region of anti-sunward plasma flow observed over the southern polar cap on orbit 6871 precedes the onset of the expansive phase of the polar magnetic substorm by 10 to 15 minutes (cf. Figure 10 and 11 ). Since at least an additional 10 minutes is required for the convection of magnetic field lines from the dayside polar cusp region to the spacecraft, it is clear that a greatly enhanced magnetic merging rate was established at the sunlit magnetopause substantially before the expansive phase of the substorm. This increase in the merging rate at the magnetopause must have occurred not more than one hour before the onset of the expansive phase of the substorm since no comparably large region of antisunward plasma flow was observed for the northern hemisphere pass of orbit 6871 one hour earlier. However, a relatively narrow zone with convection velocities of 1 to $2 \mathrm{~km}(\mathrm{sec})^{-1}$ is detected in the local morning sector during this pass (see Figure 11). Since the growth phase of the substorm commences almost concurrently with the detection of these large convection velocities, it is believed that this zone of enhanced-plasma-flow in the local morning and its subsequent expansion into the large-scale flow pattern observed one hour later are directly associated with the growth phase of this 
substorm. The onset of the growth phase of this polar magnetic substorm appears to have been triggered by a notable change in the direction of the interplanetary magnetic field in the vicinity of the earth at 1420 ( \pm 10 min.) UT (N. F. Ness, private communication). The direction of the interplanetary magnetic field changed from dominantly sunward to anti-sunward at this time. These observations of an enhanced anti-sumward plasma flow during the growth phase of this substorm are generally consistent with current ideas on the origin of substorms [cf. Axford, 1969] in which the transport and build-up of magnetic flux in the tail of the magnetosphere precede the expansive phase of the substorm.

An estimate of the electrostatic potential over the polar regions during this substorm can be obtained from the electric field observations for the southern hemisphere pass of orbit 6871 and the northern hemisphere pass of orbit 6872 . During these traversals of the polar caps the electric antenna axis was oriented approximately parallel to the spacecraft velocity vector so that the electrostatic potential, $\Phi$, can be determined by directly integrating the measured electric field $\mathrm{E}$

$$
\Phi=-\int E \mathrm{~d} \mathbf{s},
$$

where ds is an element of length-along the-satelli-te-trajectory. The actual antenna alignment for these two passes is shown by the convection velocity directions in Figure 11 (the antenna axis is 
perpendicular to the arrows in this diagram). Although the antenna axis does not remain exactly parallel to the velocity vector during these passes, the error introduced by this misalignment is small, $\leqslant 10 \%$, if the electric field is generally in dawn-dusk direction, as it is expected to be in this case [cf. Cauffman and Gurnett, 1971]. The electrostatic potential computed for these two polar passes is shown by the solid lines in Figure 14. Because of the large misalignment of the antenna axis relative to the velocity vector at middle and low latitudes during these orbits (due to the rotation of the spacecraft) the electrostatic potential cannot be determined directly for these segments of the orbits. Since the convection electric field is believed to be very small at middle and low latitudes, as observed in a frame of reference rotating with the earth, we have assumed that the electrostatic potential is constant along these segments of the orbit as shown by the dashed lines in Figure 14. Due to temporal fluctuations of the convection electric field and the nonconservative electric field produced by the magnetic perturbations accompanying the substorm, the world-wide potential distribution obtained during this orbit is expected to be subject to substantial errors attributable to these variations. However, the potential variations observed during individual polar cap crossings should be considerably less compromised by the above effects because the time interval for such measurements is relatively short. As shown in Figure 14, the maximum potential differences from dawn to dusk across the northern and southern polar regions are very 
similar, $235 \mathrm{kV}$ and $240 \mathrm{kV}$, respectively. These potential differences are much larger than the potential differences usually encountered over the polar caps with Injun 5, typically of the order of $50 \mathrm{kV}$ [Cauffman and Gurnett, 1971, Frank and Gurnett, 1971]. The potential difference of $\sim 125 \mathrm{kV}$ between the dawn and dusk regions is also quite large and cannot be accounted for by a steady-state flow pattern.

An important new relationship revealed by the charged particle observations for this substorm is that just prior to the expansive phase of the substorm the electron ( $E>45 \mathrm{keV}$ ) trapping boundary in the local late-evening sector was located about $5^{\circ}$ INV equatorward of the electric field reversal (see Figure 12). Since it has been previously established that the electric field reversal and the electron ( $\mathrm{E}>45 \mathrm{keV}$ ) trapping boundary are typically coincident within observational errors [Frank and Gurnett, 1971] this electric field-plasma relationship must be regarded as quite unusual. We attribute the poleward movement of the electric field reversal location, relative to its usual position near the trapping boundary, as being due to the rapid reconnection of field lines in the downstream magnetosheath and creation of "new" closed field lines in the distant plasma sheet which are not yet populated by energetic electrons with energies $E \geqslant 45 \mathrm{keV}$. The observation of plasma-sheet electrons-and-protons poleward of the trapping boundary and in the region of sunward convection (see the shaded portion of Figure 12) provides substantial evidence of the increased reconnection rate and 
the corresponding poleward expansion of the plasma sheet as viewed at low altitudes. The subsequent relaxation of the electric field reversal location back to its usual position near the trapping boundary during the decay phase of the substorm (see Figure 13) is interpreted as being due to a decrease in the downstream reconnection rate followed by a filling up (of the region of newly created closed field lines within the plasma sheet) with energetic electrons via gradient and/or electric drifts from adjacent regions populated with such electrons or via local electron acceleration.

One further noteworthy effect encountered during this substorm is the presence of enhanced intensities of precipitated low-energy electrons over the northern polar cap during the decay phase of the substorm. Since the magnetic field lines in this region of antisunward flow must presumably pass through the magnetosheath before connecting into the solar wind, the most apparent source for these low-energy ( $100 \mathrm{eV}$ to $1 \mathrm{keV}$ ) electrons is the high-latitude magnetosheath. If these precipitated electrons do originate from the magnetosheath, the question immediately arises as to why these electron intensities dramatically increased during the course of this polar magnetic substorm. The marked asymmetry in the electron precipitation over the northern and southern polar caps undoubtedly provides an important clue as to the origin of these electrons. The north-south asymetry in the merging rates at the sunlit magnetopause at high latitudes introduced by the radial component of the solar-wind magnetic field [cf. Frank, 1971b] and the asymmetry introduced by the seasonal 
tilt of the earth's magnetic dipole axis relative to the solar wind direction are considered the most likely asymmetries which could be responsible for the observed difference in precipitation over the northern and southern polar caps. Further examples of these electron precipitation events are being investigated to provide more information concerning the mechanisms responsible for this electron precipitation over the earth's polar caps. 


\section{ACKNOWLEDGMENTS}

We wish to thank Dr. S.-I. Akasofu for providing the magnetograms used in this study and Dr. N. F. Ness for providing the interplanetary magnetic field measurements from the Explorer 35 satellite.

This research was supported in part by the National Aeronautics and Space Administration under contracts NAS5-10625, NAS1-8141, and NASI-2973 and grant NGL16-001-002 and by the Office of Naval Research under contract NO0014-68-A-0196-0003. 
REFERENCES

Ackerson, K. L., and L. A. Frank, Correlated satellite measurements of low-energy electron precipitation and ground-based observations of a visible auroral arc, J. Geophys. Res., 77, 1128, 1972.

Aggson, T. L., Results of magnetospheric electric field measurements, Abstract from the conference on Electric Fields in the Magnetosphere, Rice University, Houston, Texas, 1969.

Akasofu, S.-I., Polar and Magnetic Substorms, D. Reidel, Dordrecht, The Netherlands, 1968.

Axford, W. I., Magnetospheric convection, Rev. Geophys., I, 421, 1969.

Carpenter, D. L., F. Walker, R. E. Barrington, and D. J. McEwen, Alouette 1 and 2 observations of abrupt changes in whistler rate and of VLF noise variations at the plasmapause: A satellite ground study, J. Geophys. Res., 73, 2929, 1968.

Cauffman, D. P., and D. A. Gurnett, Double-probe measurements of convection electric fields with the Injun 5 satellite, J. Geophys. Res., 76, 6014, 1971 . 
Cauffman, D. P., and D. A. Gurnett, Satellite measurements of high latitude convection electric fields, submitted for publication, Space Sci. Rev., 1972.

Choy, L. W., R. L. Arnoldy, W. Potter, P. Kinter, and L. J. Cahill, Jr., Field-aligned particle currents near an auroral arc, J. Geophys. Res., 76, 8279, 1971.

Craven, J. D., Temporal variations of electron intensities at low altitudes in the outer radiation zone as observed with satellite Injun 3, J. Geophys. Res., 71, 5643, 1966.

Dungey, J. W., Interplanetary magnetic field and the auroral zones, Phys. Rev. Lett., 6, 47, 1961.

Frank, L. A., Plasma in the earth's polar magnetosphere, J. Geophys. Res., 76, 5202, 1971a.

Frank, I. A., Comments on a proposed magnetospheric model, J. Geophys. Res., 76, 2512, 1971b.

Frank, L. A., Relationship of the plasma sheet, ring current, trapping boundary, and plasmapause-near the-magnetic equator and local midnight, J. Geophys. Res., 76, 2265, 1971c. 
Frank, L. A., and K. L. Ackerson, Observations of charged particle precipitation into the auroral zone, J. Geophys. Res., 76 , $3612,1971$.

Frank, L. A., and K. L. Ackerson, Local-time survey of plasma at low altitudes over the auroral zones, J. Geophys. Res., in. press, 1972a.

Frank, L. A., and K. L. Ackerson, Rapid temporal variations of plasmasheet electron intensities at low altitudes, J. Geophys. Res., in preparation, $1972 \mathrm{~b}$.

Frank, L. A., and D. A. Gurnett, Distributions of plasmas and electric fields over the auroral zones and polar caps, J. Geophys. Res., 76, 6829, 1971.

Gurnett, D. A., G. W. Pfeiffer, R. R. Anderson, S. R. Mosier, and D. P. Cauffman, Initial observations of VLF electric and magnetic fields with the Injun 5 satellite, J. Geophys. Res., $74,4631,1969$.

Gurnett, D. A., and L. A. Frank, VLF hiss and related plasma observations in the-polar magnetosphere, J. Geophys. Res.-, I7, $172,1972$. 
Haerendel, G., Electric fields and their effects in the ionosphere, Proc. Leningrad Symposium on Solar-Terrestrial Physics, p. 62, D. Reidel, Dordrecht, The Netherlands, 1971.

Haerendel, G., and R. Lust, Electric fields in the ionosphere and magnetosphere, in Particles and Fields in the Magnetosphere, edited by B. M. McCormac, p. 213, D. Reidel, Dordrecht, The Netherlands, 1970.

Heikkila, W. J., and J. D. Winningham, Penetration of magnetosheath plasma to low altitudes through the dayside magnetospheric cusps, J. Geophys. Res., 76, 883, 1971.

Heppner, J. P., Electric field variations during substorms: OGO-6 measurements, Rep. X-645-72-10, Goddard Space Flight Center, Greenbelt, Md., 1972 .

Hultqvist, B., Auroras and polar substorms: Observations and theory, Rev. Geophys., 7, 129, 1969.

Kennel, C. F., Consequences of a magnetospheric plasma, Rev. Geophys., 7, $379,1969$.

McPherron, R. L., Growth phase of magnetospheric substorms, J. Geophys. Res., 75, 5592, 1970. 
Mozer, F. S., and U. V. Fahleson, Parallel and perpendicular electric fields in an aurora, Planet. Space Sci., 18, 1563, 1970.

Potter, W. E., Rocket measurements of auroral electric and magnetic fields, J. Geophys. Res., 75, 5415, 1970.

Rostoker, G., Polar magnetic substorms, Rev. Geophys., 10, 157, 1972.

Vasyliunas, V. M., A survey of low-energy electrons in the evening sector of the magnetosphere with OGO 1 and OGO 3, J. Geophys. Res., 73, 2839, 1968.

Wescott, E. M., J. D. Stolarik, and J. P. Heppner, Electric fields in the vicinity of auroral forms from motions of barium vapor releases, J. Geophys. Res., 74, 3469, 1969. 
FIGURE CAPTIONS

Plate 1 Energy-time spectrogram of the precipitated electron intensities observed for a northern hemisphere pass over the auroral zone at about 18.8 hours MLT. Several distinct "inverted V" electron precipitation events are observed at 0027:10 to 0028:20 UT.

Plate 2 Energy-time spectrogram of the precipitated electron intensities observed for a northern hemisphere pass over the auroral zone at about 23.0 hours MLT. Several "inverted V" electron precipitation bands are evident at 0702:20 to 0703:25 UT. The plasma sheet extends from about 0703:25 UT to the end of the pass at 0707:25 UT.

Plate 3 Energy-time spectrogram of the precipitated electron intensities observed for a northern hemisphere pass over the auroral zone at about 24.0 hours MLT. Several "inverted V" events are evident at 0622:55 to 0624:45 UT. The plasma sheet is encountered at 0624:45 to 0627:30 UT.

Plate 4 Energy-time spectrogram of the precipitated electron intensities observed for a northern hemisphere pass over the auroral zone at about- 0.5 hours-MET. A- moderate "inverted $V^{\prime \prime}$ event is observed at 0644:40 to 0645:15 UT and the plasma sheet extends from 0645:15 to 0647:30 UT.

Note: $\quad$ Plates 1 through 4 are to be published in color. 
Figure 1 Simultaneous observations of VF hiss, convection electric fields, and charged particle intensities for a noonmidnight meridional pass over the southern polar cap and auroral zone. Note that the polar cusp is located in the zone of eastward convection just poleward of the electric field reversal and the electron ( $E>45 \mathrm{keV}$ ) trapping boundary.

Figure 2 A polar diagram showing the direction and magnitude of the convection velocity components associated with the electric field observations in Figure 1. The polar cusp is located within the zone of eastward convection at 0850:10 to 0852:10 UT.

Figure 3 Two further examples illustrating the relationship between the polar cusp (shaded), the convection electric field, and the electron $(E>45 \mathrm{keV})$ trapping boundary (vertical dashed lines).

Figure 4 A polar diagram showing the direction and magnitude of the convection velocity components for the southern hemisphere polar pass of orbit 7561 in Figure 3 . The convection velocity in the polar cusp, from about 0830 to 0832 UT, is westward, indicating that the "stagnation point" for the polar-cusp plasma flow is located east of the-spacecraft-for this example.

Figure 5 A polar diagram showing the direction and magnitude of the convection velocity components for the northern 
hemisphere polar pass of orbit 6802 in Figure 3. The maximum low-energy electron intensities in the polar cusp are encountered essentially coincident with the electric field reversal at 2224:20 UT.

Figure 6 The electric field and precipitated electron energy fluxes corresponding to the energy-time spectrogram of Plate 1. The electric field reversal, $\sim 50 \mathrm{mV}(\mathrm{m})^{-1}$, at 0027:45 to 0028:05 UT occurs within the most energetic of the "inverted V" bands.

Figure 7 The electric fields and precipitated electron energy fluxes corresponding to the energy-time spectrogram of Plate 2. Note the large, $\sim 50 \mathrm{mV}(\mathrm{m})^{-1}$, irregular electric field variations associated with the "inverted $V^{\prime \prime}$ events and the absence of any comparable fluctuations within the plasma-sheet region.

Figure 8 The electric field and precipitated electron energy fluxes corresponding to the energy-time spectrogram of Plate 3. Note the large irregular electric field fluctuations associated with the "inverted $V$ " events and the large, $\sim 65 \mathrm{mV}(\mathrm{m})^{-1}$, electric fields near the equatorward boundary of the plasma sheet. The equatorward termination of this convection zone is coincident with the plasmapause location as determined with simultaneous VIF electric field measurements. 
Figure 9 The electric field and precipitated electron energy fluxes corresponding to the energy-time spectrogram of Plate 4.

Figure 10 Superposed H-traces from the magnetograms of a series of selected auroral zone observatories during the polar magnetic substorm of February 24, 1970.

Figure 11. A polar plot of the direction and magnitude of the convection velocity components detected during the magnetic substorm of February 24, 1970. The time periods of these polar passes are shown shaded in Figure 10.

Figure 12 The simultaneous electric field and charged particle measurements during the southern hemisphere polar pass of orbit 6871 , approximately 10 to 15 minutes before the onset of the expansive phase of the substorm.

Figure 13 Simultaneous electric field and charged particle measurements for the northern hemisphere polar pass of orbit 6872 , shortly after the expansive phase of the substorm.

Figure 14 The electrostatic potential over the polar regions as determined by integrating the electric field components along the spacecraft trajectory. The dashed lines correspond to regions at low- and mid-latitudes where the electrostatic potential cannot be computed directly because of unfavorable alignment of the electric antenna axis, and - where the convection electric fields have been assumed to be zero. 


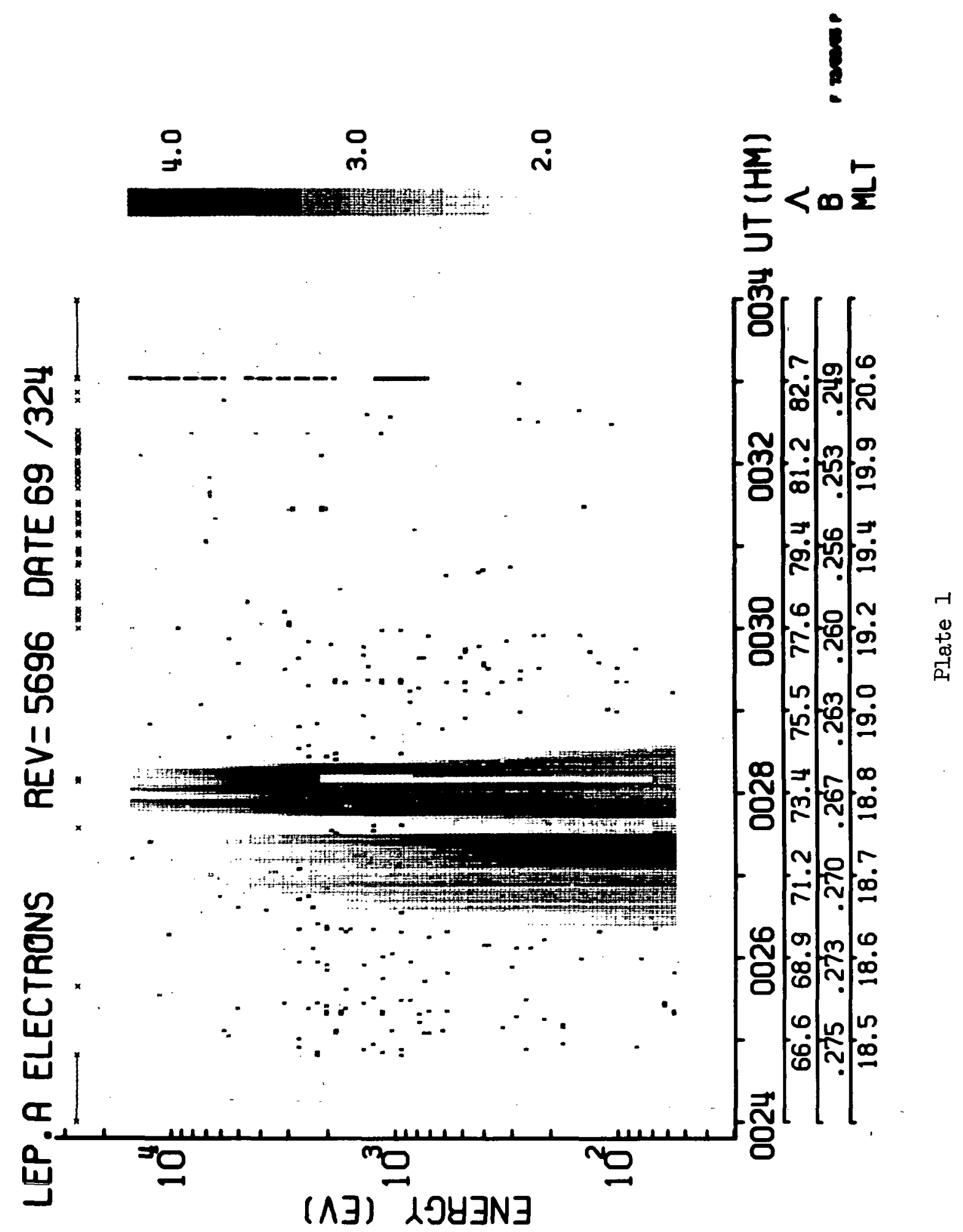




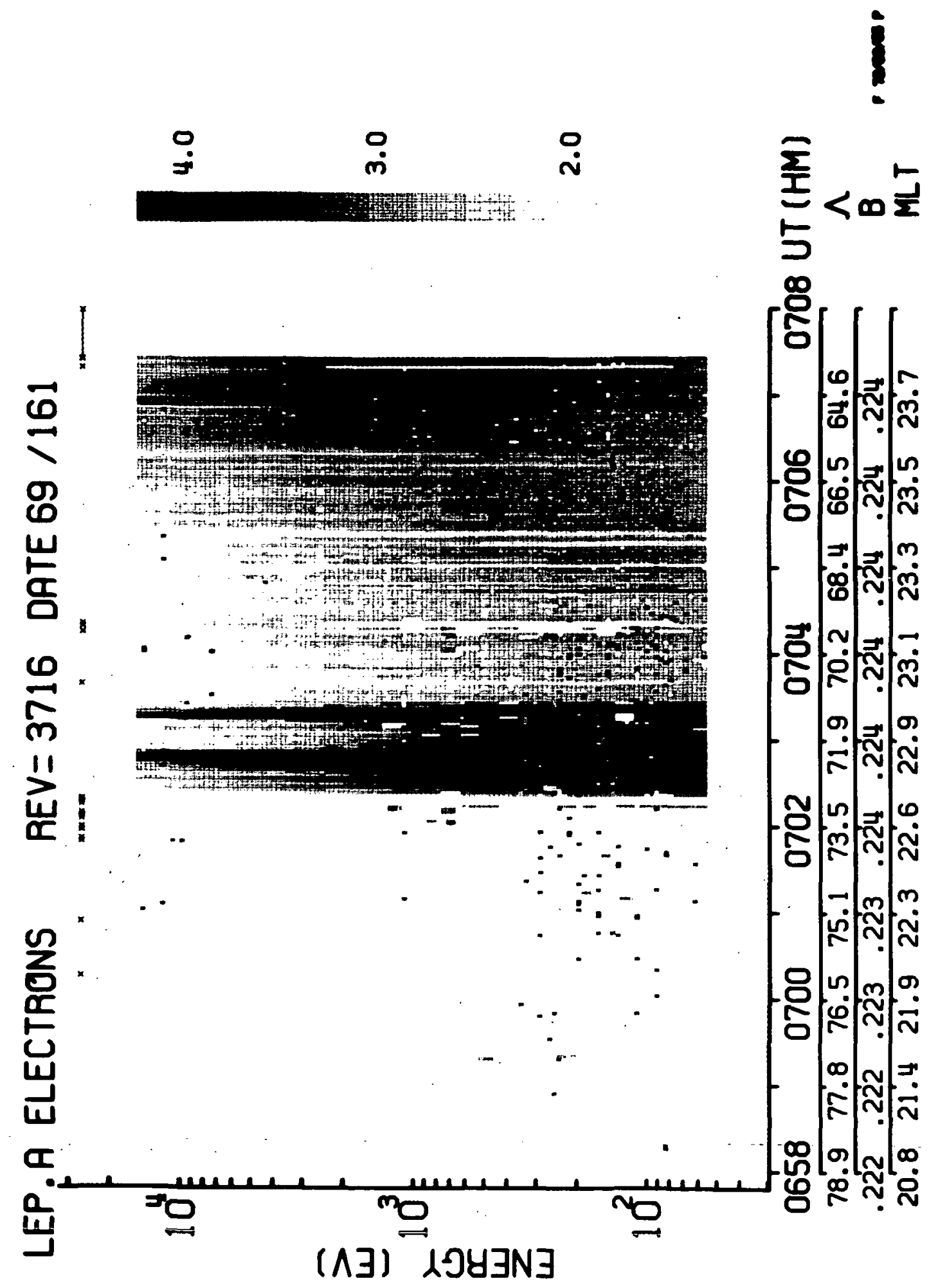




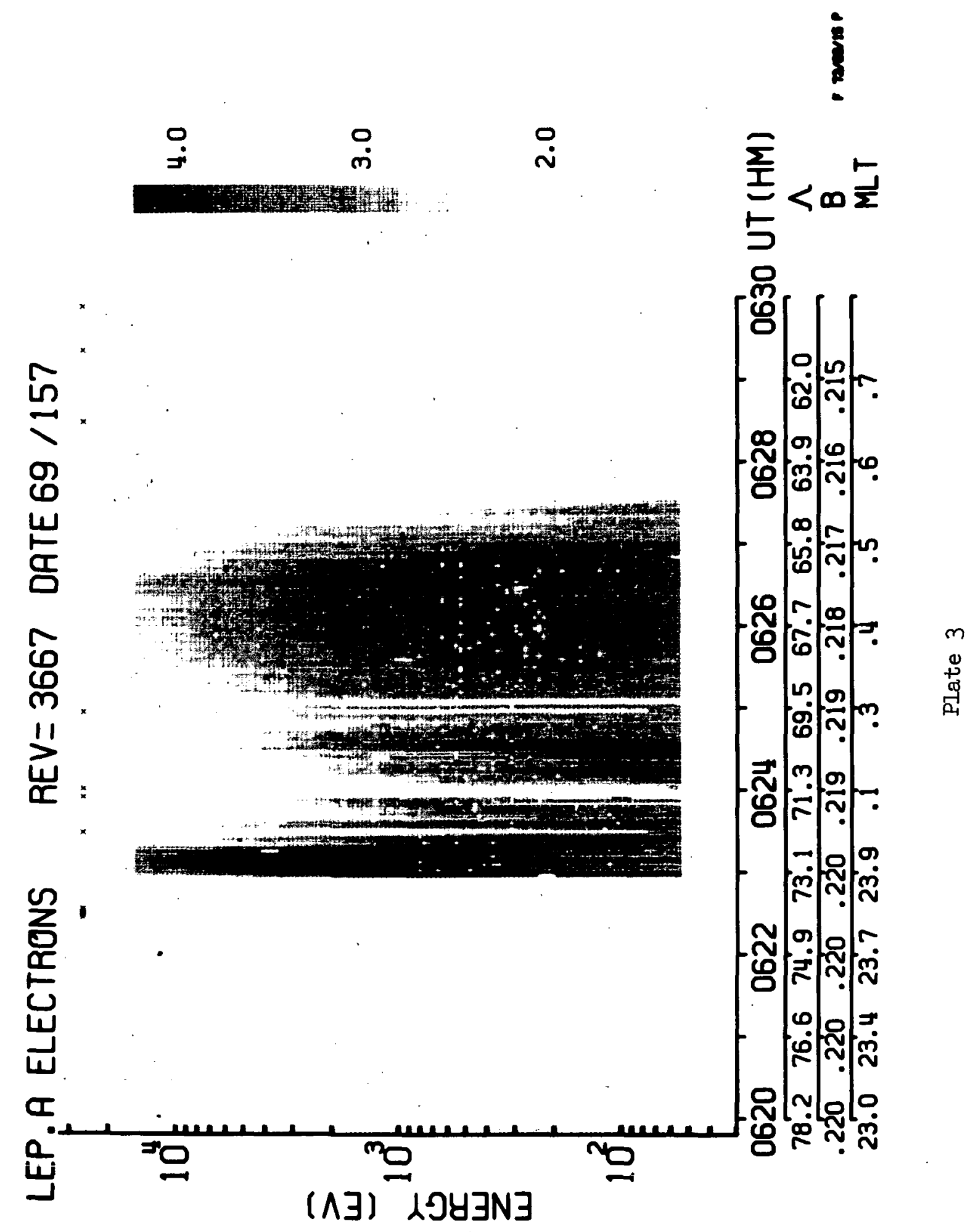




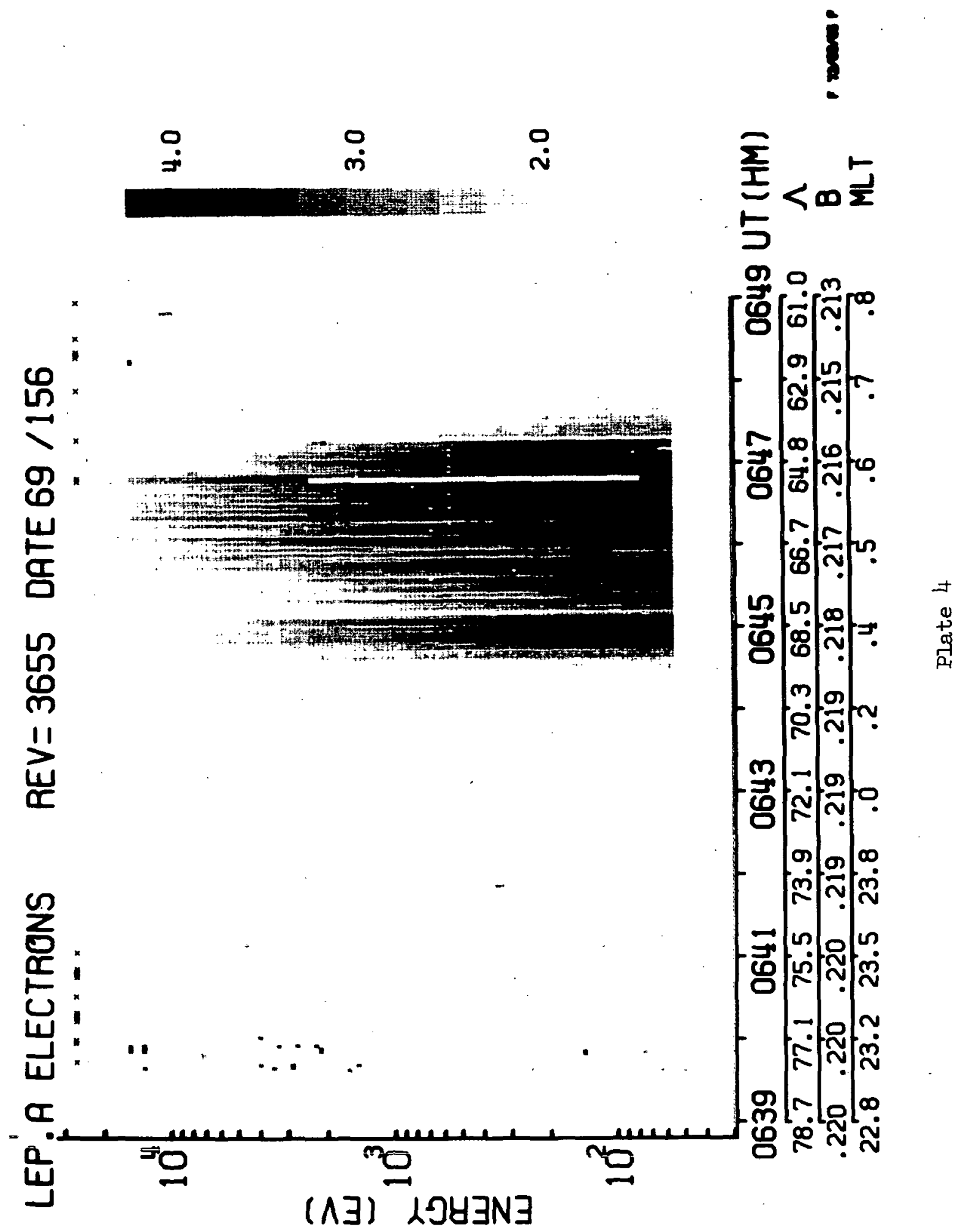



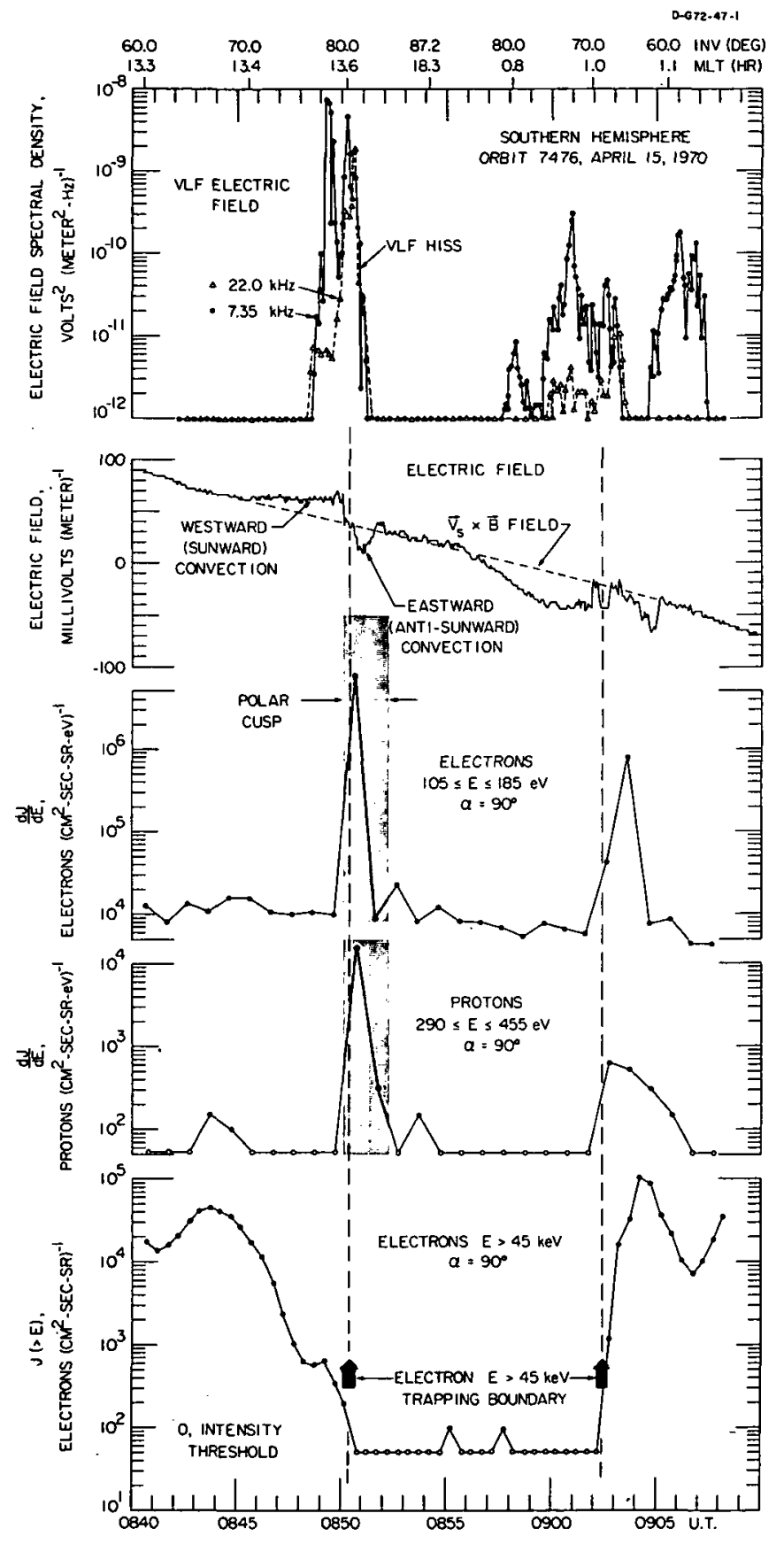

Figure 1 


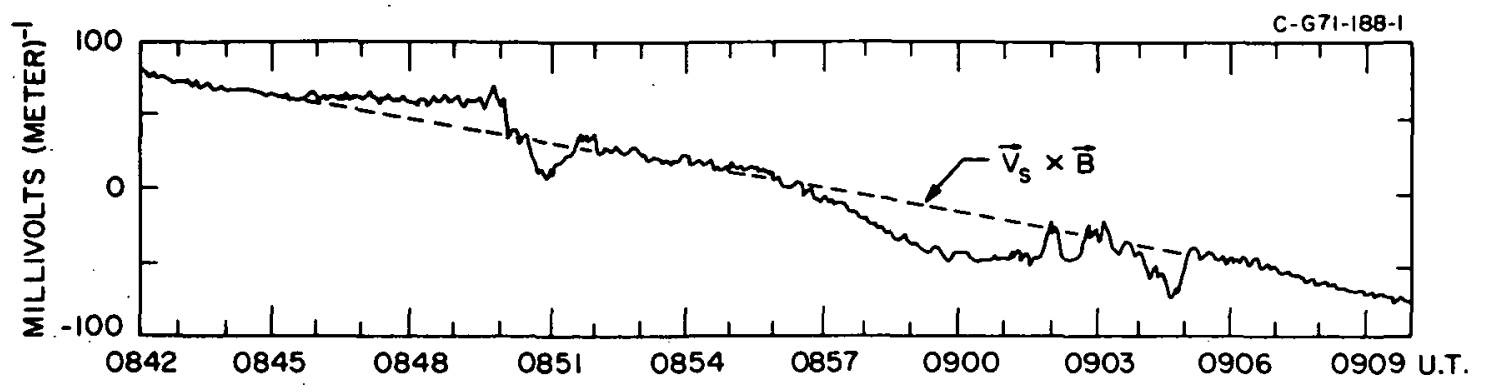

SOUTHERN HEMISPHERE ORBIT 7476 APRIL 15, 1970

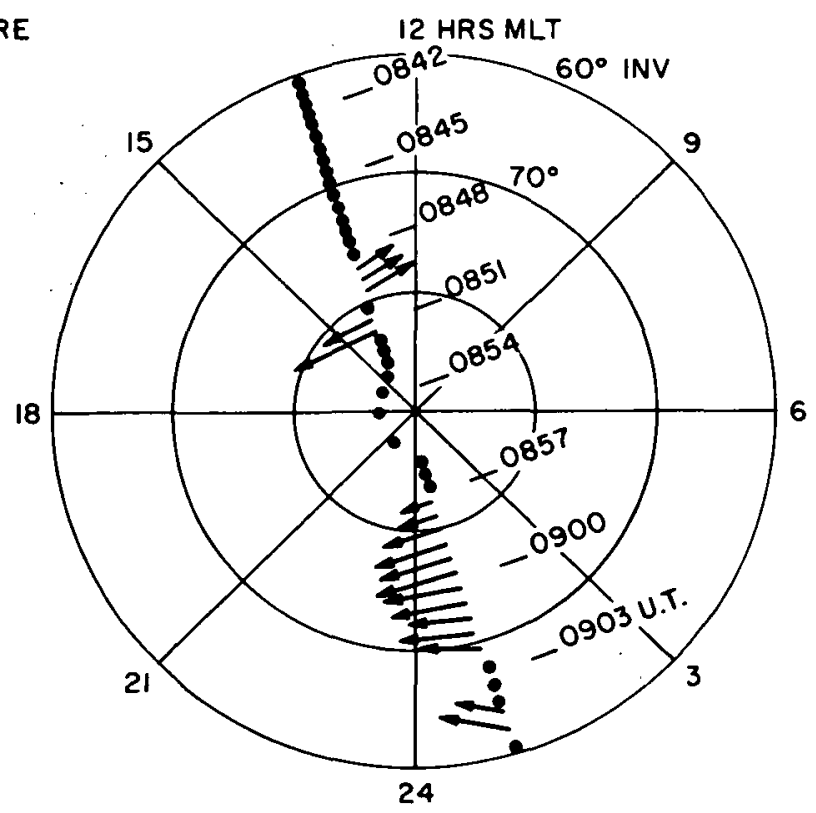

CONVECTION VELOCITY COMPONENT

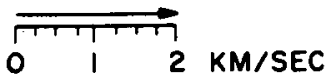

Figure 2 


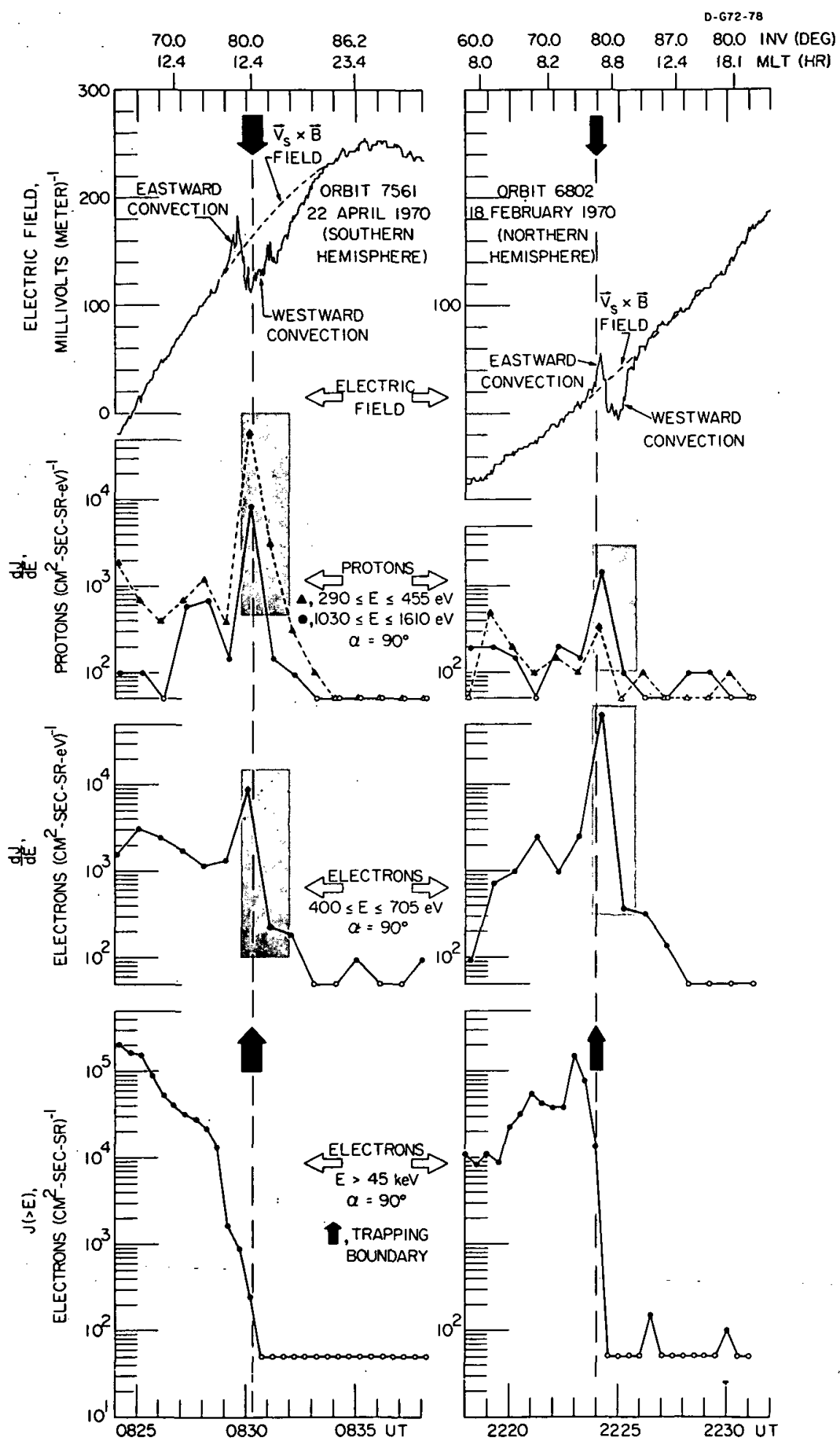

Figure 3 


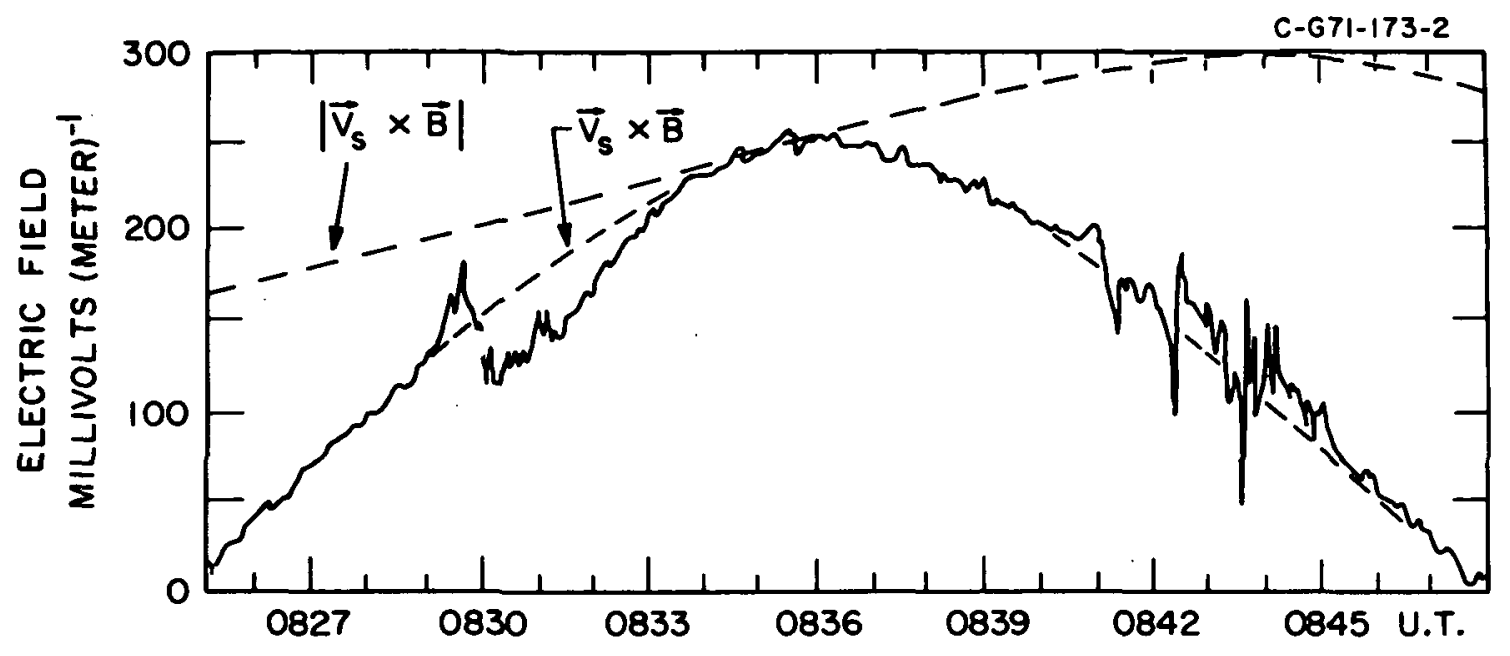

SOUTHERN HEMISPHERE

ORBIT 7561

APRIL 22, 1970

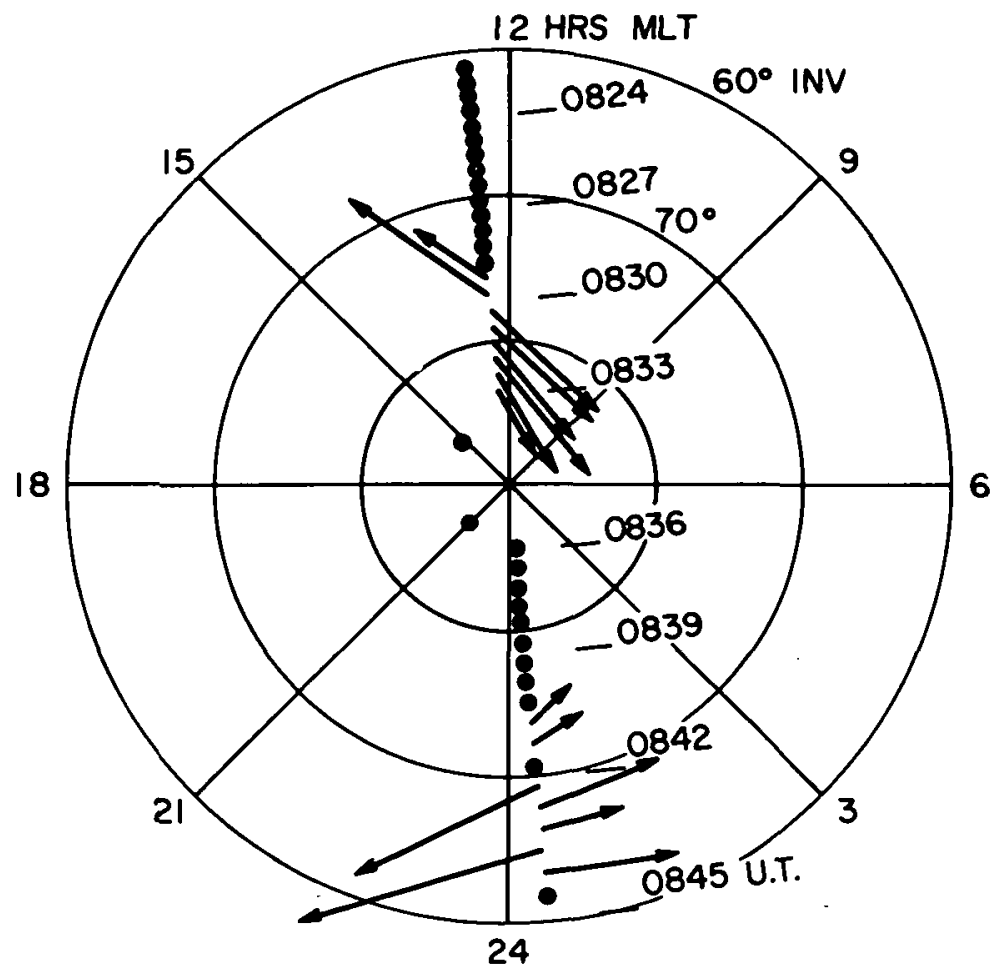

CONVECTION VELOCITY COMPONENT

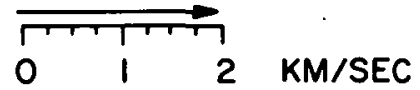

Figure 4 

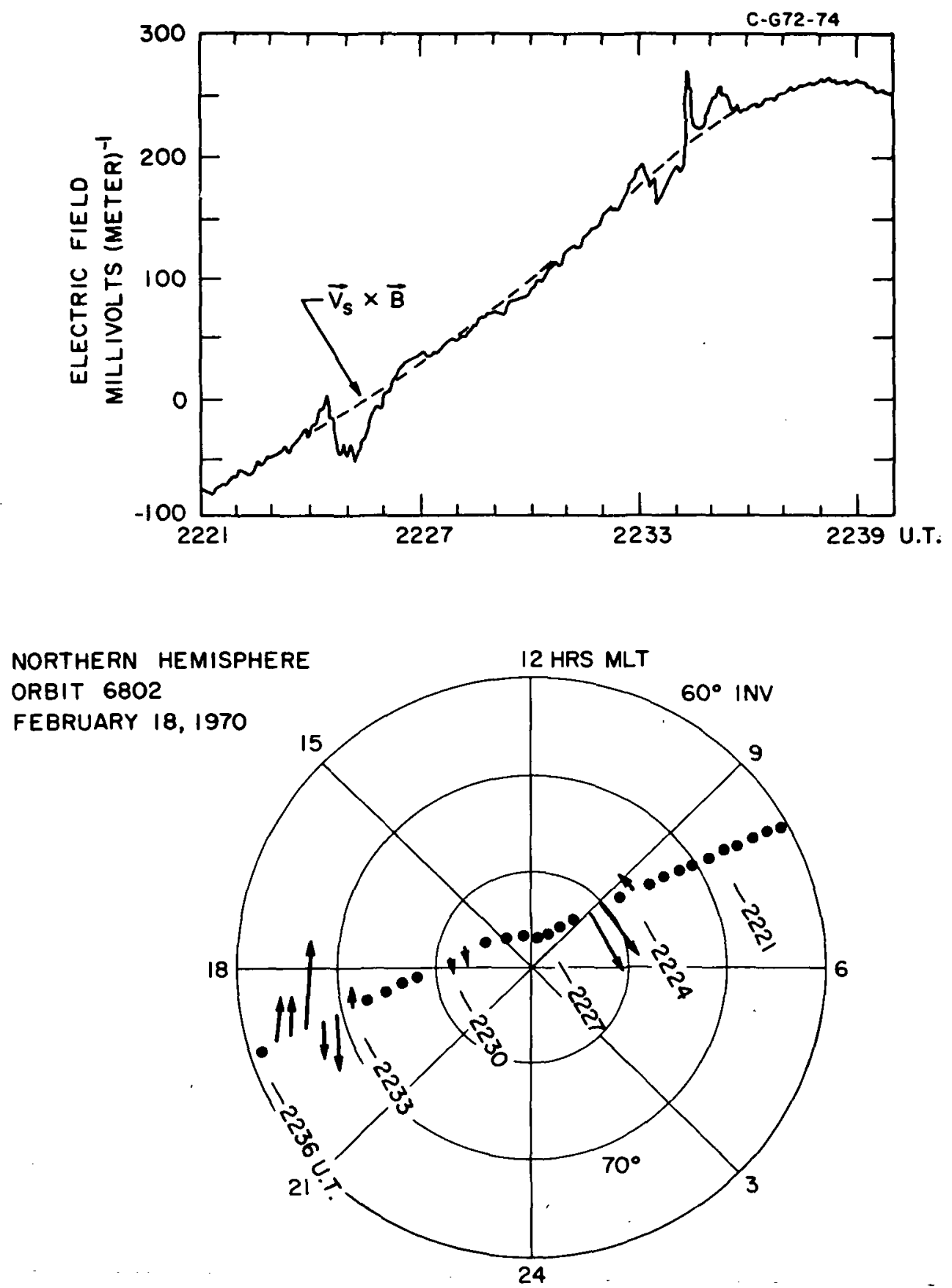

MEASURED COMPONENT OF CONVECTION VELOCITY

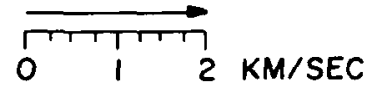

Figure 5 


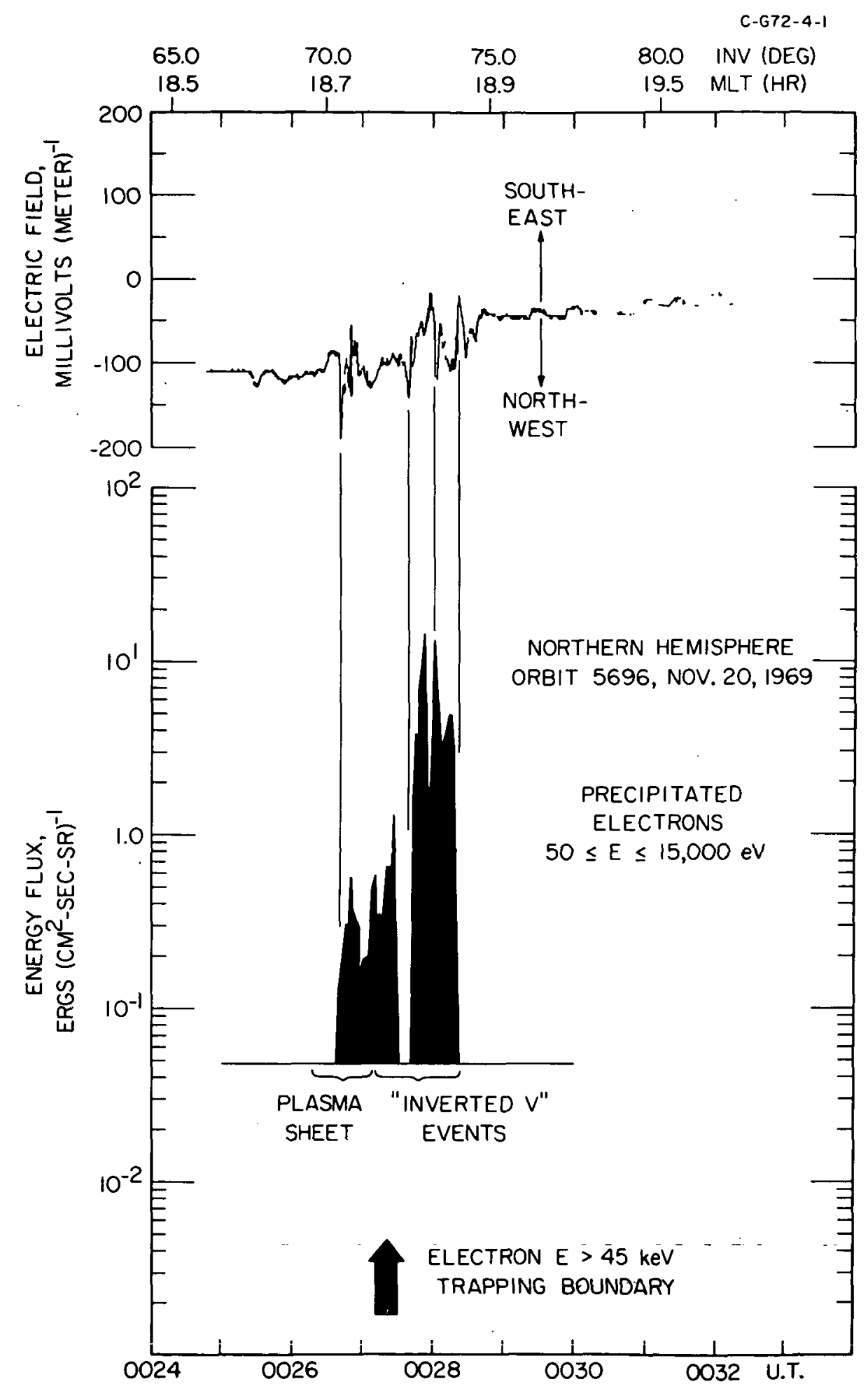

Figure 6 


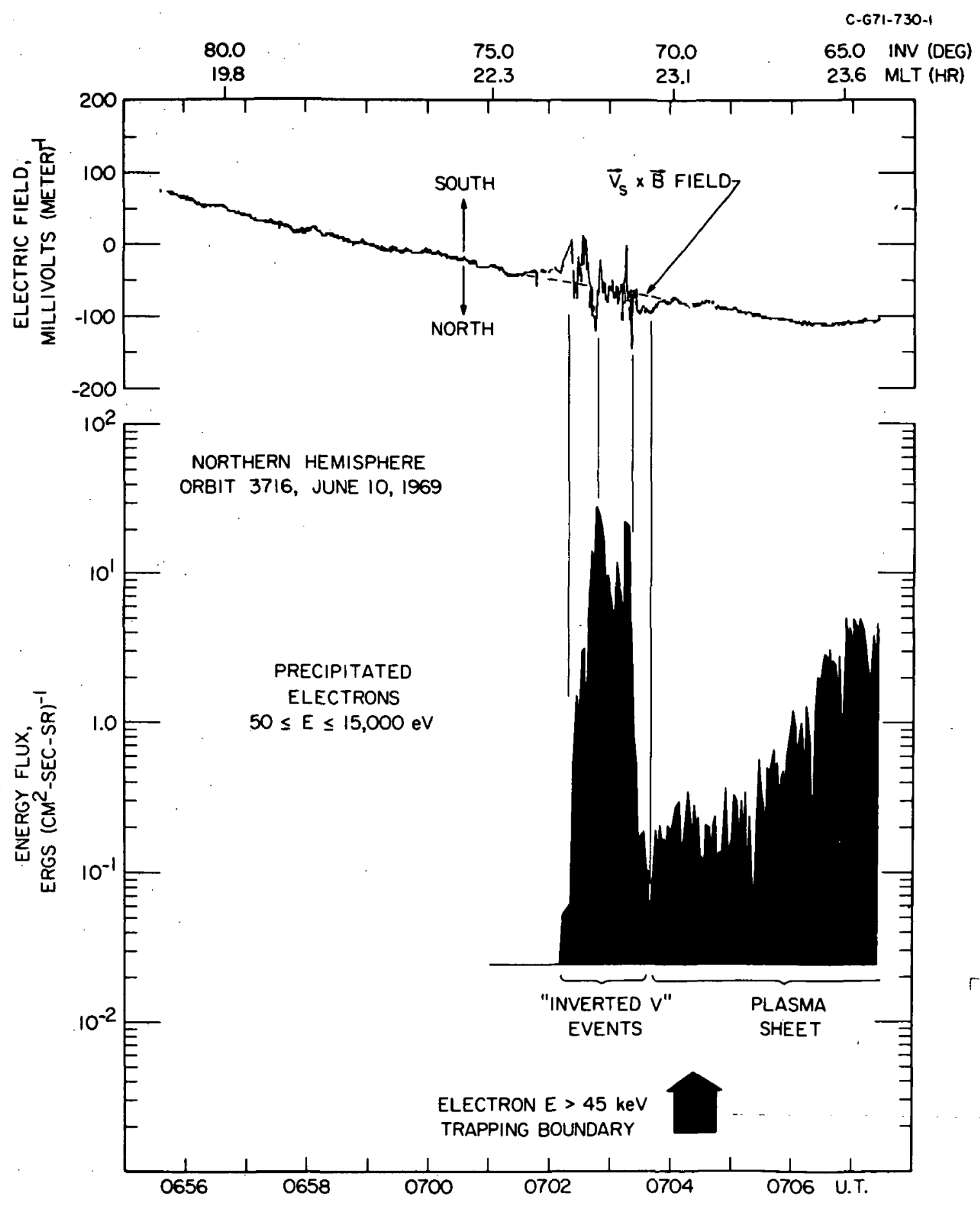




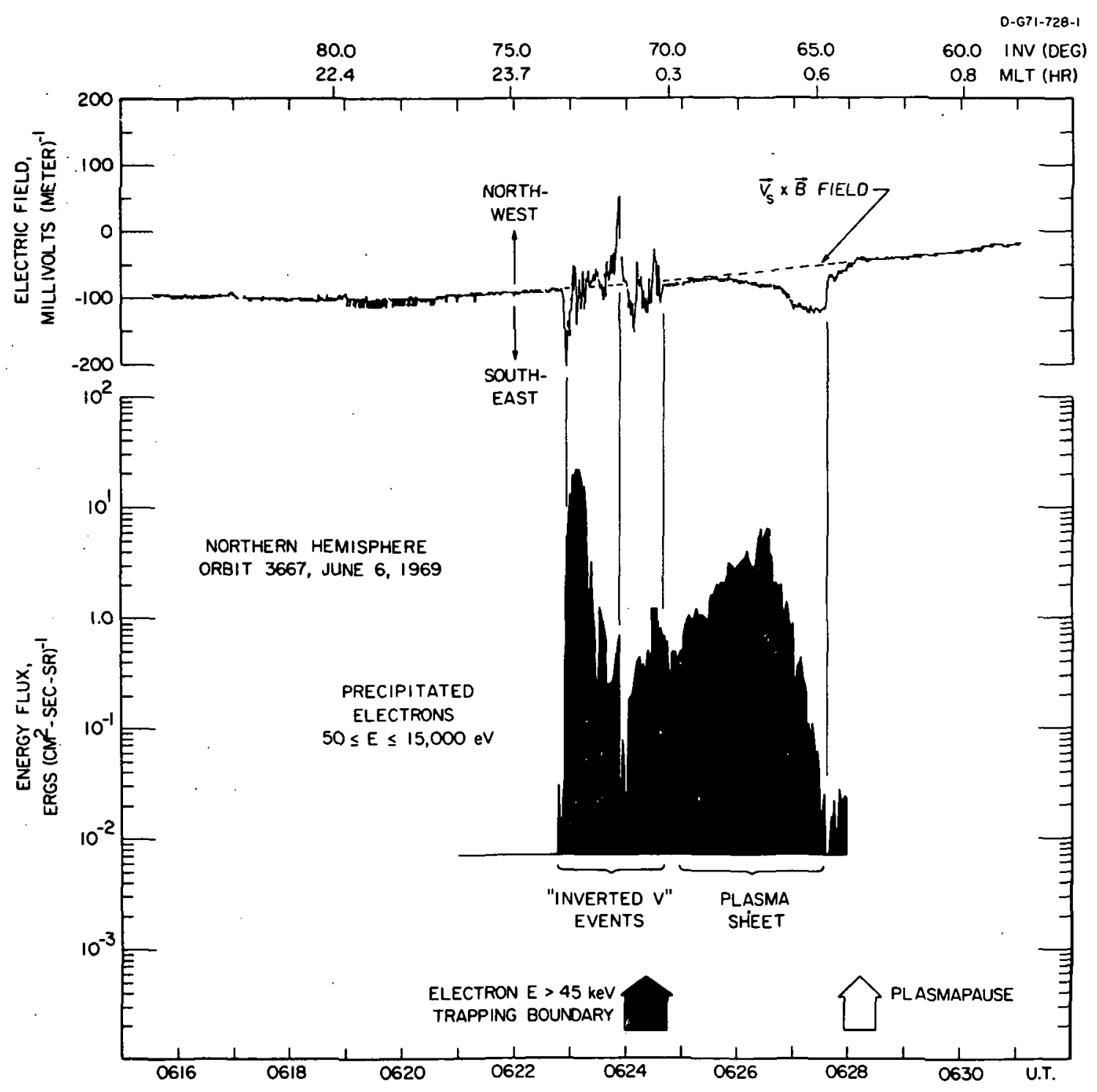

Figure 8 


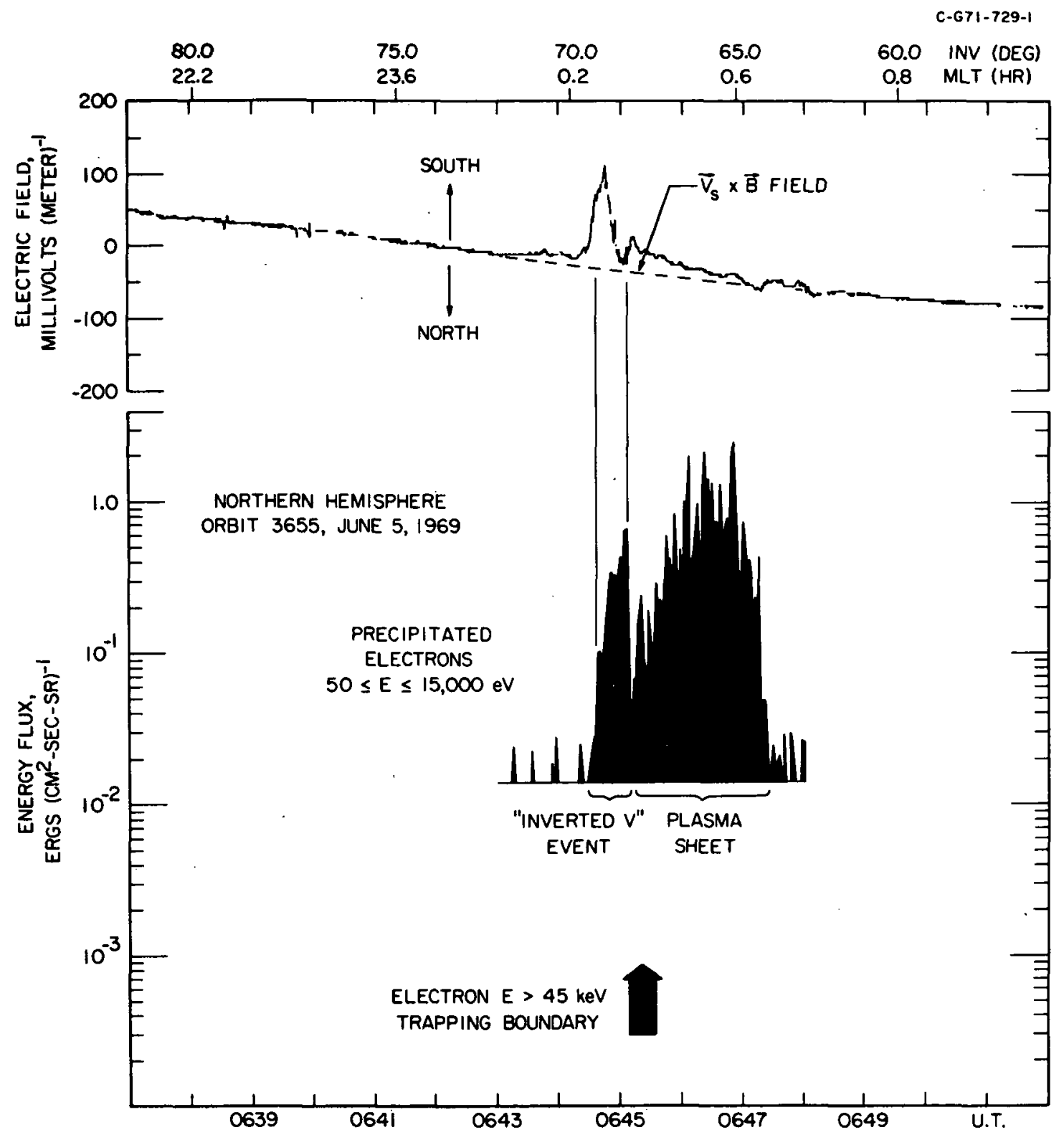

Figure 9 


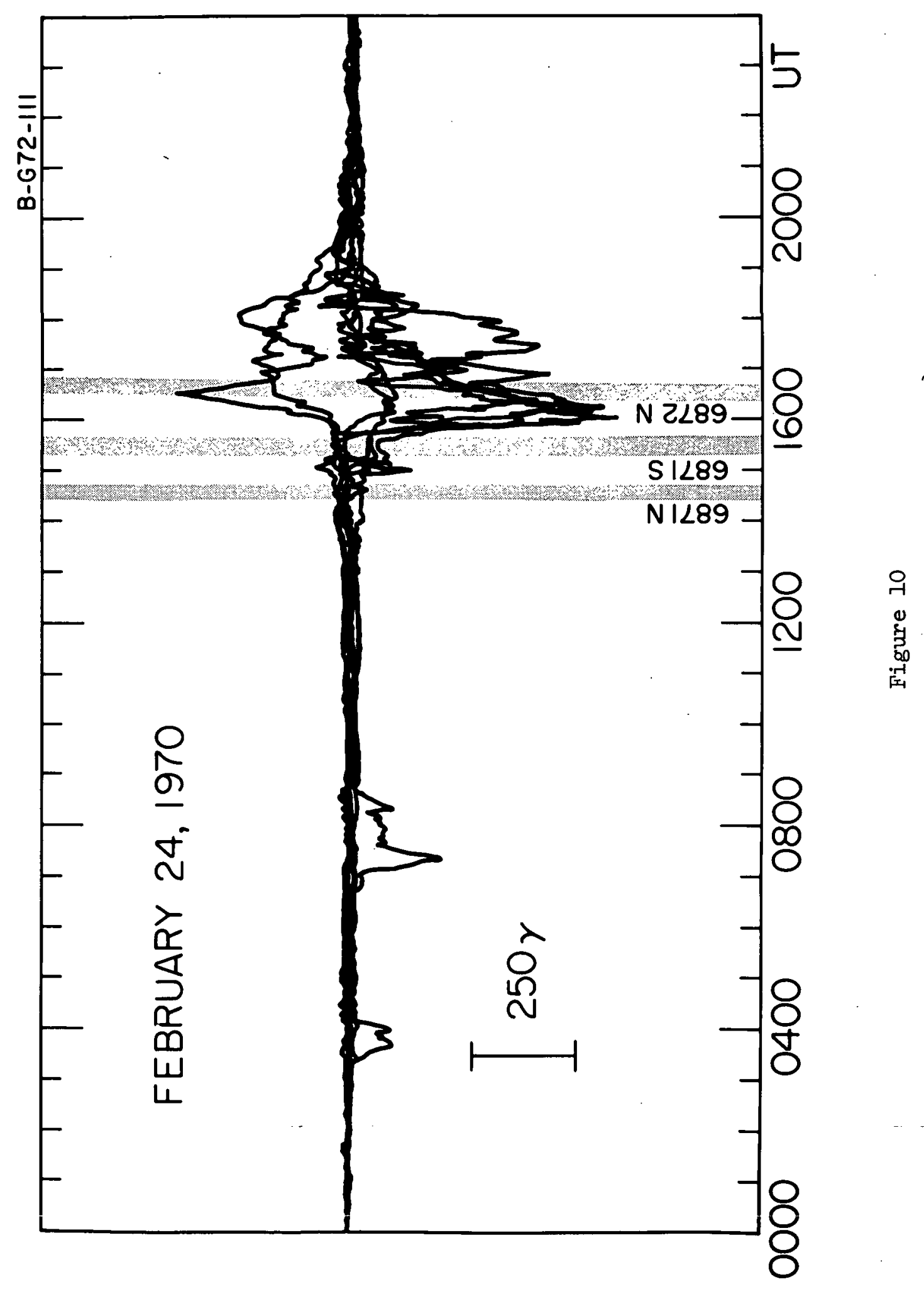



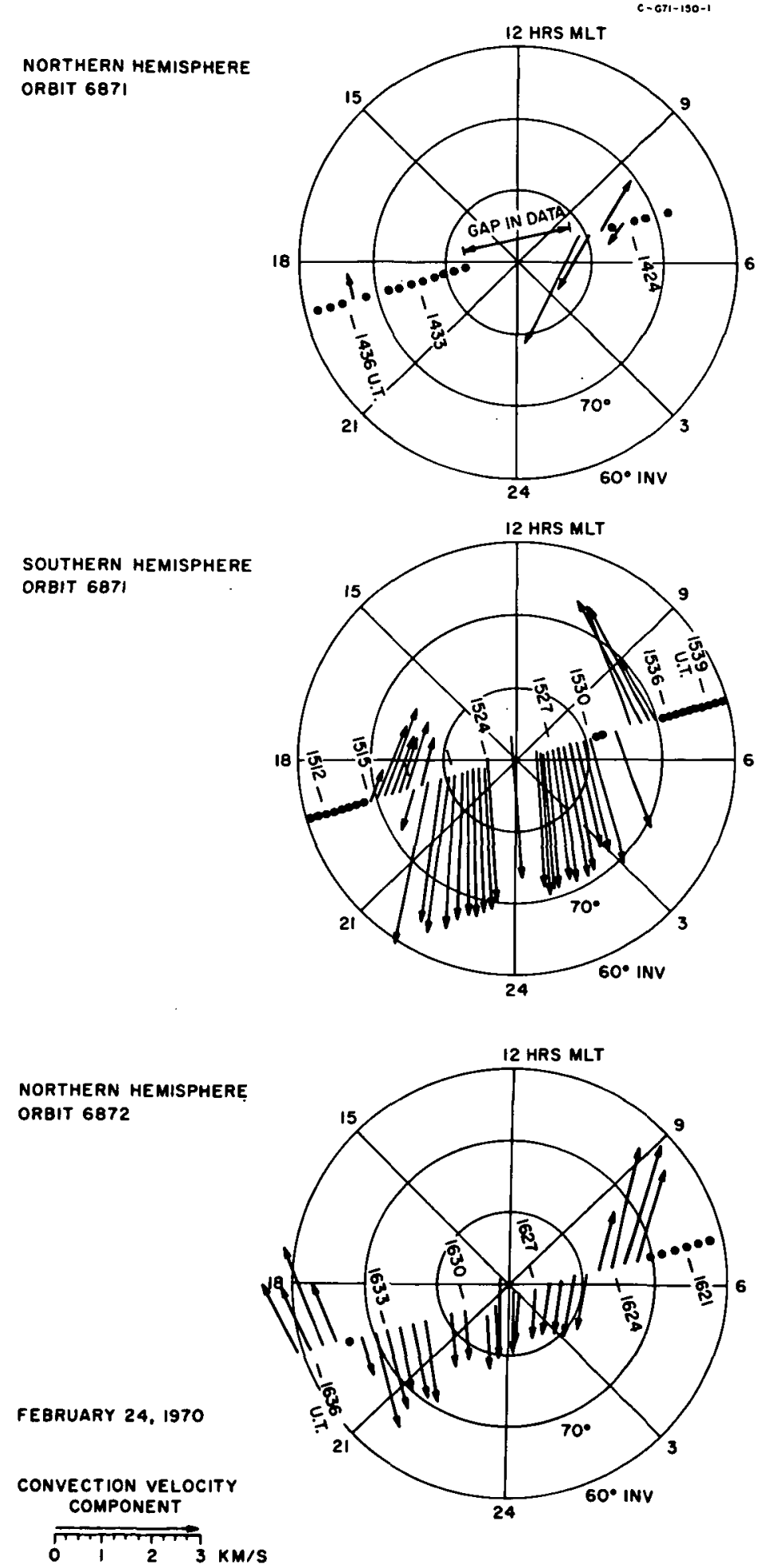

Figure 11 


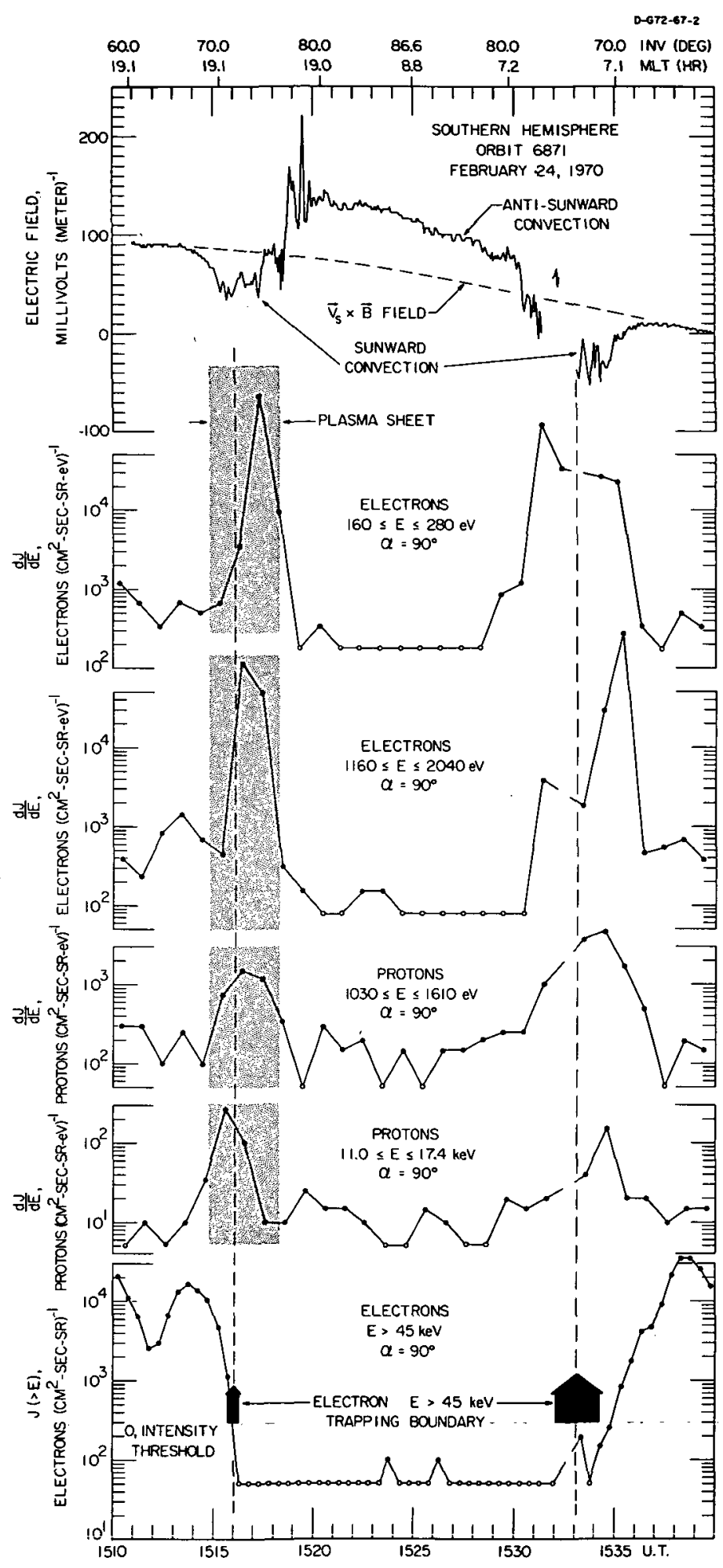

Figure 12 


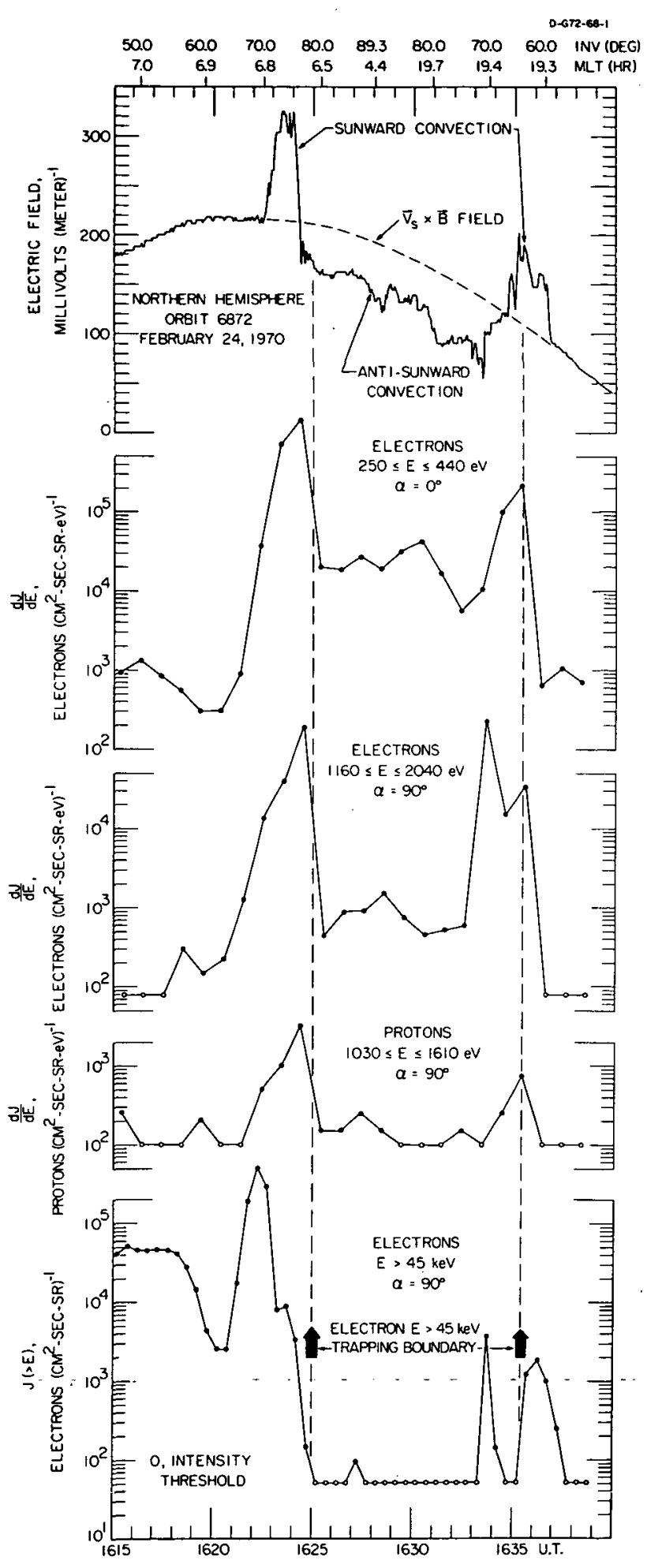

Figure 13 


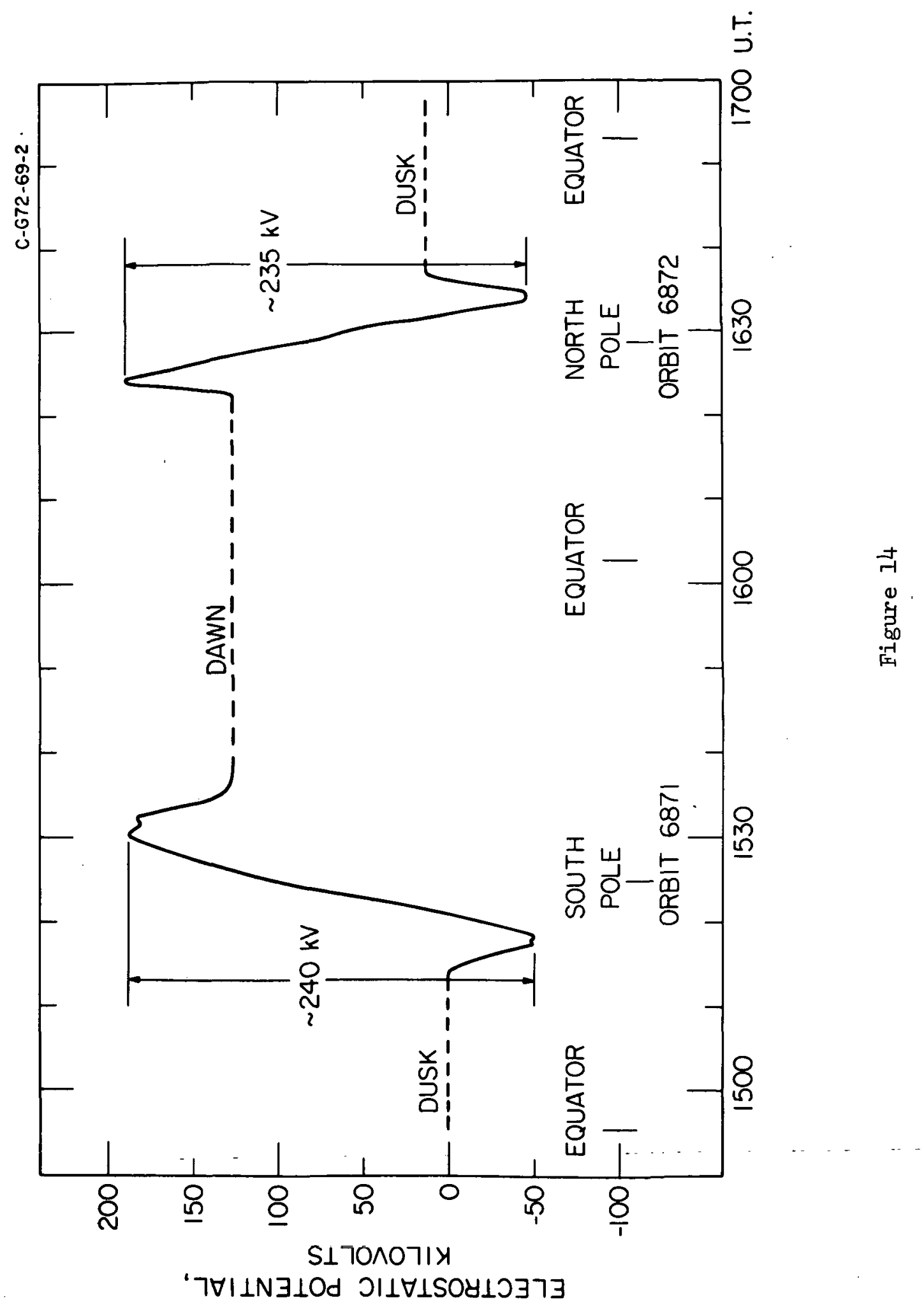

